\title{
Mechanisms and Drug Development in Atrial Fibrillation
}

\author{
David Calvo, ${ }^{1}$ David Filgueiras-Rama, ${ }^{1}$ and José Jalife
}

Department of Cardiology, Arrhythmia Unit, Hospital Universitario Central de Asturias and Instituto de Investigación Sanitaria del Principado de Asturias, Oviedo, Spain (D.C.); Fundación Centro Nacional de Investigaciones Cardiovasculares Carlos III (CNIC), Madrid, Spain (D.F.-R., J.J.); Department of Cardiology, Arrhythmia Unit, Hospital Clinico Universitario San Carlos, Madrid, Spain (D.F.-R.); Centro de Investigación Biomédica en Red de Enfermedades Cardiovasculares (CIBERCV), Madrid, Spain (D.F.-R., J.J.); and Center for Arrhythmia Research, Department of Internal Medicine, University of Michigan, Ann Arbor, Michigan (J.J.)

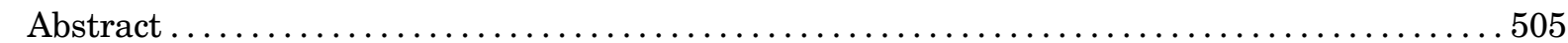

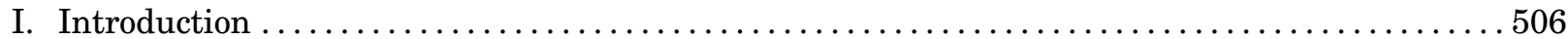

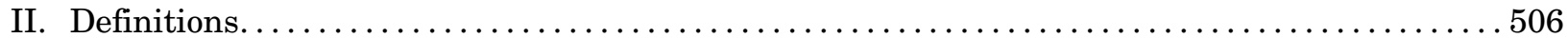

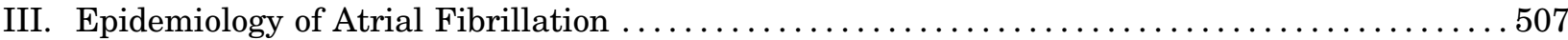

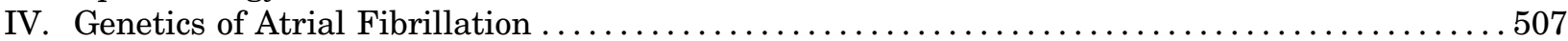

V. Pathophysiology of Atrial Fibrillation ................................... 509

A. Mechanisms of Atrial Fibrillation Initiation and Maintenance.................... 509

B. Triggered Activity, Reentry, and the Initiation of Atrial Fibrillation ................ 509

C. Ionic Bases of Triggered Activity .................................... 510

D. Ion Channels and Reentry in Atrial Fibrillation............................. 511

VI. Status of Antiarrhythmic Drugs in Atrial Fibrillation............................ 512

A. Atrial Selective Ion Channel Blockers ................................... 512

B. Acetylcholine-Activated Inward Rectifying $\mathrm{K}^{+}$Current and Atrial Fibrillation ......... 513

C. Multichannel Blockade Drugs that Minimize Adverse Events ................... 514

VII. New Drug Uses and New Molecular Mechanisms ............................. 514

A. Targeting Inward-Rectifying $\mathrm{K}^{+}$Channels, Insights from Chloroquine Use in

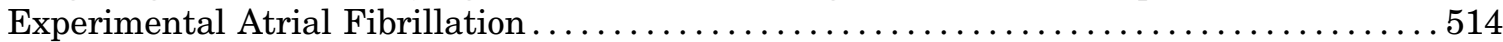

B. Intracellular $\mathrm{Ca}^{2+}$ Regulation as a Target for Atrial Fibrillation Therapy ............5 515

C. Gap-Junction Therapy Aiming at Homogenous Impulse Propagation $\ldots \ldots \ldots \ldots \ldots \ldots . \ldots 17$

VIII. Novel Targets in Atrial Fibrillation ......................................... 517

A. Ion Channels, Electrical Remodeling, and the Progression of Atrial Fibrillation. ........ 517

B. Remodeling and Upstream Therapies in Atrial Fibrillation. . . . . . . . . . . . . . . . . 517

C. Nonpharmacologic Targets: Obesity, Adiposis, and Inflammation in Atrial Fibrillation . . 519

IX. Atrial Fibrillation and Sleep Apnea ...................................... 520

X. Challenges and Opportunities in New Anti-atrial Fibrillation Drug Development..........520

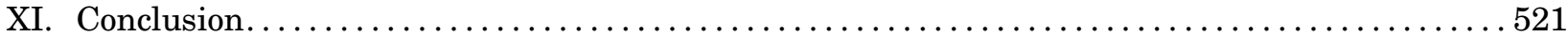

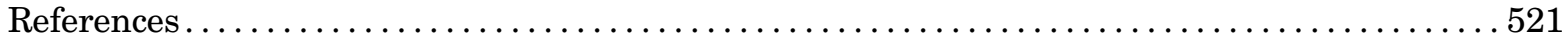

\begin{abstract}
Atrial fibrillation is a highly prevalent cardiac arrhythmia and the most important cause of embolic stroke. Although genetic studies have identified an increasing assembly of AF-related genes, the impact of these genetic discoveries is yet to be realized. In addition, despite more than a century of research and speculation, the molecular and cellular mechanisms underlying AF
\end{abstract}

have not been established, and therapy for $\mathrm{AF}$, particularly persistent AF, remains suboptimal. Current antiarrhythmic drugs are associated with a significant rate of adverse events, particularly proarrhythmia, which may explain why many highly symptomatic $\mathrm{AF}$ patients are not receiving any rhythm control therapy. This review focuses on recent advances in AF research, including its

Address correspondence to: Dr. José Jalife, Center for Arrhythmia Research, Department of Internal Medicine, University of Michigan, 2800 Plymouth Road, Ann Arbor, MI 48109. E-mail: jjalife@med.umich.edu

This work was supported in part by National Institutes of Health National Heart, Lung, and Blood Institute [Grant R01 HL122352] to J.J.

${ }^{1}$ D.C. and D.F.-R. contributed equally to this work.

https://doi.org/10.1124/pr.117.014183. 
epidemiology, genetics, and pathophysiological mechanisms. We then discuss the status of antiarrhythmic drug therapy for AF today, reviewing molecular mechanisms, and the possible clinical use of some of the new atrial-selective antifibrillatory agents, as well as drugs that target atrial remodeling, inflammation and fibrosis, which are being tested as upstream therapies to prevent AF perpetuation. Altogether, the objective is to highlight the magnitude and endemic dimension of AF, which requires a significant effort to develop new and effective antiarrhythmic drugs, but also improve $\mathrm{AF}$ prevention and treatment of risk factors that are associated with AF complications.

\section{Introduction}

Atrial fibrillation (AF) is the most common arrhythmia seen by the clinician. It affects more than 33 million people worldwide (Chugh et al., 2014) and is also the number one cause of hospitalization for arrhythmias (Hart, 2003; Heijman et al., 2014; Miyasaka et al., 2006). Prevalence increases with advancing age and so are its associated comorbidities, like heart failure (Sardar et al., 2016). AF is characterized by rapid and irregular activation of the atria without discrete $P$ waves on the surface electrocardiogram (ECG). The pathophysiology of AF is complex, involving dynamic interactions among several factors, including substrate, triggers, and perpetuators, and the therapeutic approaches/strategies are informed by the disease progression from initiation of the abnormal electrical rhythm to its maintenance.

Many drugs have been tried in persistent AF with limited success (Camm et al., 2010). Several class IA, IC, and III drugs, as well as class II drugs (beta-blockers), are moderately effective in maintaining sinus rhythm after conversion of atrial fibrillation. However, they increase adverse events, including proarrhythmia, and some like disopyramide, quinidine, and sotalol, may increase mortality (Lafuente-Lafuente et al., 2015). In fact, antiarrhythmic drug therapy in general improves patients' symptom scores and exercise tolerance; however, large randomized trials have failed to show a mortality benefit with a rhythm-control compared with a rate-control strategy (Halsey and Chugh, 2014). Therefore, the availability of new oral anticoagulant drugs that overcome the intrinsic disadvantages of warfarin has shifted the focus of drug development toward enabling widespread application of effective thromboprophylaxis with oral anticoagulants, particularly in low-risk patients with AF (Lip et al., 2012; Kirchhof et al., 2016).

On the other hand, the development of new mapping and catheter-based ablation technologies, which have made the procedure safer, easier to perform, and more effective after a single attempt, has greatly improved the outcomes in patients with paroxysmal AF. However, success rates for persistent $\mathrm{AF}$ ablation remain far lower than paroxysmal $\mathrm{AF}$ and there is large variation in the strategies used worldwide, (Cappato et al., 2005; Calkins et al., 2007; Matsuo et al., 2007) which highlights the need and offers new opportunities for the development of a new generation of drugs for the prevention and termination of $\mathrm{AF}$.

This article is not intended as a comprehensive review of the pharmacology of antiarrhythmic drugs, as excellent reviews on the subject have appeared in the recent literature (Camm et al., 2012; Hanley et al., 2016; Kanagaratnam et al., 2017). Instead, we focus on recent advances in $\mathrm{AF}$ research, including its genetics, epidemiology, and pathophysiological mechanisms. We then discuss the status of antiarrhythmic drug therapy for $\mathrm{AF}$ today, reviewing molecular mechanisms and the possible clinical use of some of the new atrial-selective antifibrillatory agents (see Visual Abstract), as well as drugs that target remodeling and inflammation that are being tested as upstream therapies to prevent $\mathrm{AF}$ perpetuation.

\section{Definitions}

According to the 2016 and 2017 expert consensus documents (Kirchhof et al., 2016; Calkins et al., 2017), paroxysmal $\mathrm{AF}$ is defined as recurrent $\mathrm{AF}$ episodes that terminate spontaneously or with intervention within 7 days of onset; persistent $\mathrm{AF}$ is defined as continuous $\mathrm{AF}$ that is sustained beyond 7 days; long-standing persistent $\mathrm{AF}$ is defined as continuous $\mathrm{AF}$ of greater than 12-month duration. The first diagnosed AF refers to AF that has not been diagnosed before, irrespective of the duration of the arrhythmia or the presence and severity of AF-related symptoms. From a clinical point of view, the latter is important as more than $50 \%$ of patients with a first diagnosed $\mathrm{AF}$ episode will not experience recurrences over long-time follow up in the absence of antiarrhythmic drugs, cardiac structural abnormalities, and significant comorbidities (Pappone et al., 2008). Early persistent AF is a new term defined as continuous AF of more than 7-day duration but less than 3-month duration. The latter subdivision is reasonable for patients who are candidates for an AF ablation procedure, because better results are obtained with shorter duration of the persistent AF. The term permanent $\mathrm{AF}$ is defined as $\mathrm{AF}$ in which the presence of

ABBREVIATIONS: ACEI, angiotensin converting enzyme inhibitors; APD, action potential duration; ARB, angiotensin II receptor blockers; $\mathrm{DAD}$, delayed afterdepolarization; DF, dominant excitation frequency; EAD, early afterdepolarization; EPL, eplerenone; FFA, free fatty acid; GWAS, genome-wide association studies; $\mathrm{HF}$, heart failure; $\mathrm{I}_{\mathrm{K} 1}$, inward rectifying $\mathrm{K}^{+}$current; $\mathrm{I}_{\mathrm{KACh}}$, acetylcholine-activated inward rectifying $\mathrm{K}^{+}$current; $\mathrm{I}_{\mathrm{Kr}}$, fast component of the delayed rectifier $\mathrm{K}^{+}$current; $\mathrm{I}_{\mathrm{Ks}}$, slow component of the delayed rectifier $\mathrm{K}^{+}$current; $\mathrm{I}_{\mathrm{Kur}}$, ultrarapid component of the delayed rectifier $\mathrm{K}^{+}$current; $\mathrm{I}_{\mathrm{Na}}$, fast inward $\mathrm{Na}^{+}$current; $\mathrm{K}_{2 \mathrm{P}}$, two-pore $\mathrm{K}^{+}$channels; $\mathrm{MRB}$, mineralocorticoid receptor blocker; PV, pulmonary vein; RAAS, renin-angiotensin-aldosterone system; SAC, stretch-activated channels; $\mathrm{SK}$, small-conductance Ca ${ }^{2+}$-activated $\mathrm{K}^{+}$channels; SNPs, single nucleotide polymorphisms; WK, Wenxin Keli. 
the $\mathrm{AF}$ is accepted by the patient and physician, and no further attempts will be made either to restore or maintain sinus rhythm (Calkins et al., 2017).

\section{Epidemiology of Atrial Fibrillation}

$\mathrm{AF}$ represents a global health care problem that predominantly affects developed nations, North America being the region with the highest prevalence and incidence rates (Chugh et al., 2014). AF prevalence in North America almost triples the rates of the AsiaPacific region. Overall, both incidence and prevalence rates have been progressively increasing in the world population (Colilla et al., 2013; Zoni-Berisso et al., 2014), which may result in more than 50 million AF patients worldwide by 2030 . These estimations may even underestimate future AF burden worldwide. Data to make estimations have been obtained primarily from Western Europe and North America, with very limited representation from vast populations in developing countries (Colilla et al., 2013; Chugh et al., 2014; Zoni-Berisso et al., 2014). The latter underscores substantial differences in healthcare systems and resources among regions, which makes it difficult to detect and diagnose $\mathrm{AF}$, especially silent $\mathrm{AF}$ episodes without symptoms (Fitzmaurice et al., 2007).

Current AF prevalence in the general adult population of Europe ranges from 1.9\% to 2.9\% depending on the country (Zoni-Berisso et al., 2014), although more importantly, the data are consistent with prevalence rates that double the reported data one decade earlier (Murphy et al., 2007). In the United States, the prevalence rate also increased for Medicare beneficiaries older than 65 years, with an absolute growth of $4.5 \%$ (from $4.1 \%$ to $8.6 \%$ ) in the period 1993-2007 (Piccini et al., 2012). Moreover, AF prevalence varies with age and sex. In individuals younger than 50 years and older than 80 years, AF prevalence ranges from $0.1 \%$ to $10 \%-18 \%$, respectively (Zoni-Berisso et al., 2014). Globally, AF prevalence is higher in men than in women, with a 1.5: 1 ratio considering worldwide data (Chugh et al., 2014).

$\mathrm{AF}$ is frequently associated with cardiac disease and with cardiac/noncardiac comorbidity. The most frequent comorbidities are hypertension, heart failure (HF), diabetes, and obesity (Cea-Calvo et al., 2007; Di Pasquale et al., 2013; Zoni-Berisso et al., 2014). Moreover, onethird of AF patients have at least three associated comorbidities, with a low percentage of $\mathrm{AF}$ patients presenting with presumably no heart disease or comorbidities, although most studies do not provide information on the extent of diagnostic testing to rule out all risk factors and comorbidities currently associated with $\mathrm{AF}$ (Wyse et al., 2014).

AF progression from paroxysmal or persistent episodes to permanent stages shows a slow but continuous trend that may reach $30 \%$ after 5 years of follow up despite appropriate clinical management (Jahangir et al., 2007). Progression is often related to the development of underlying heart disease, which also increases the risk of adverse cardiovascular events and mortality (Jahangir et al., 2007; Potpara et al., 2012; Banerjee et al., 2013). Moreover, AF may be associated with symptoms, sometimes disabling, and often resistant to antiarrhythmic drug therapy as reported in real-life surveys, in which symptoms may persist in more than $50 \%$ of patients (Chiang et al., 2012; Kirchhof et al., 2014). The latter often requires hospitalization and invasive interventional procedures such as ablation, which leads to a significant impact on healthcare costs (Zoni-Berisso et al., 2014). Although acute decompensation of $\mathrm{HF}$ is the leading cause of hospitalization in the persistent and permanent forms of $\mathrm{AF}$, proarrhythmic events from antiarrhythmic drugs are the most frequent causes of hospitalization among patients with paroxysmal AF (Chiang et al., 2012). Current antiarrhythmic drugs are associated with a significant rate of withdrawals due to adverse events (excluding proarrhythmia), which varies from $4 \%$ to $23 \%$ depending on the antiarrhythmic drug (Lafuente-Lafuente et al., 2015). The latter may explain why a large percentage $(\sim 50 \%)$ of highly symptomatic AF patients is not receiving any rhythm control therapy (Kirchhof et al., 2014). Altogether, the foregoing highlights the magnitude and endemic dimension of $\mathrm{AF}$, which requires a significant effort to develop new and effective antiarrhythmic drugs, but also improve AF prevention and treatment of risk factors that are associated with $\mathrm{AF}$ complications.

\section{Genetics of Atrial Fibrillation}

The risk of developing AF is intimately associated with clinical risk factors as diabetes, hypertension, $\mathrm{HF}$, and smoking, among others (Benjamin et al., 1994; Schnabel et al., 2009). Integration of risk factors makes it possible to predict short-to-midterm AF risk development using a model based on clinical variables routinely used in a conventional clinical setting (Alonso et al., 2013). Emerging research in genetics during the first decade of the 21 st century suggests that $\mathrm{AF}$ cases in the general population also have a significant genetic component, beyond traditional risk factors (Fox et al., 2004). Thus, the inclusion of familial AF (defined as occurrence of $\mathrm{AF}$ in a first-degree relative) as an additional variable further improves $\mathrm{AF}$ risk prediction based on clinical risk factors. The latter becomes especially relevant when familial $\mathrm{AF}$ is related to a first-degree relative younger than 65 years (Lubitz et al., 2010b). In fact, the risk of AF increases with decreasing age at $\mathrm{AF}$ onset in the youngest affected relative (Arnar et al., 2006; Oyen et al., 2012).

The genetic basis of $\mathrm{AF}$ varies from monogenic $\mathrm{AF}$ families and isolated AF cases, in which the reported mutations have large effect sizes and are directly responsible for causing the trait, to genetic variants with small effect sizes that confer an increased risk of 
the disease. Although linkage analysis and genotyping can identify causative rare mutations related to $\mathrm{AF}$, the use of recent next-generation sequencing technology in genetic association studies enables to investigate the co-occurrence of genetic variants among $100 \mathrm{~s}$ of $1000 \mathrm{~s}$ of single nucleotide polymorphisms (SNPs) in affected individuals. Both genetic approaches may have important clinical implications. Thus, mutations identified in monogenic AF pedigrees have shown either gainof-function or loss-of-function in genes encoding potassium or sodium channel subunits (Chen et al., 2003; Xia et al., 2005; Das et al., 2009; Li et al., 2009), respectively, both leading to APD shortening and favoring reentrant activity. Rare mutations have been also associated with higher burden of triggered activity or enhanced action potential activity from intracardiac neurons (Olson et al., 2006; Scornik et al., 2006; Li et al., 2009). The later would theoretically increase acetylcholine release, leading to a heterogeneous functional substrate for $\mathrm{AF}$ initiation (Sarmast et al., 2003).

A large body of work suggests strongly that AF is heritable. Standard genetic techniques have led to the documentation of several chromosomal loci and genes in which rare mutations can cause dominantly inherited $\mathrm{AF}$. Some such genes encode myocardial potassium (KCNQ1, KCNA5, KCNE5, KCNJ2, and KCNE2) and sodium (SCN5A, SCN1B, SCN2B, and SCN3B) channels, potassium-adenosine triphosphate channels (ABCC9), nucleoporin-155 (NUP155), and gap junction protein connexin 40 (GJA5) (Lubitz et al., 2010a; Judge, 2012). In addition, genome-wide association studies (GWAS) have suggested that, similar to other cardiovascular diseases, established AF loci only explain a moderate proportion of disease risk, suggesting that further genetic discovery, with an emphasis on common variations, in populationbased studies could be of great value for AF risk assessment and potentially determine the response to therapies (Weng et al., 2017a). Recent data have shown that both genetic predisposition and validated clinical risk factors are associated with $\mathrm{AF}$ risk, which enables establishing that a low-risk clinical profile is associated with delay of $\mathrm{AF}$ onset, despite an underlying high polygenic risk (Andrade et al., 2014). In individuals older than 55 years of age from the Framingham cohort and predominant European ancestry, the average lifetime risk of AF was recently reported to be $37 \%$, although the $\mathrm{AF}$ risk ranged from $20 \%$ to $50 \%$ among individuals in the lowest to the highest tertiles of both polygenic and clinical risk, respectively (Weng et al., 2018).

Some initial population-based studies have started to assess the influence of common SNPs related to $\mathrm{AF}$ on the response to antiarrhythmic drug therapy. A common SNP (rs10033464) on chromosome 4q25 (near the pairedlike homeodomain transcription factor 2 gene; PITX2), has been independently associated with successful reduction in symptomatic $\mathrm{AF}$ burden (a composite score for frequency, duration, and severity of symptoms). Carriers of the variant allele at rs10033464 responded favorably to class I antiarrhythmic drugs, whereas wild types responded better to class III antiarrhythmic drugs (Parvez et al., 2012). However, the mechanism for such a difference has not been elucidated; it may be mediated through effects of distant genes and particularly of PITX2 (Gudbjartsson et al., 2007), which encodes a transcription factor (PITX2c) important for pulmonary vein development and determination of left and right atrial asymmetry during cardiac development. Heterozygous deletion of PITX2c (the cardiac isoform of PITX2) in mice has been associated with shortening of the left atrial APD and higher risk of AF (Kirchhof et al., 2011). Moreover, microarray analysis of PITX2 null-mutant and control mouse hearts have revealed upregulation of KCNQ1 (Abraham et al., 2010), a potassium channel gene that has been associated with gain-of-function mutations in familial AF. Data from atrial specific PITX2-deficient mice have also shown gain-of-function of Kir2.1 (Chinchilla et al., 2011), which is intimately related to favoring reentrant activity, leading to AF (Van Wagoner, 2003; Girmatsion et al., 2009). Antiarrhythmic drug outcomes in patients with $\mathrm{AF}$ have been also related to the reninangiotensin-aldosterone system and common angiotensinconverting enzyme insertion/deletion polymorphism. The deletion/insertion of a 287-bp intronic DNA segment resulting in double-deletion or insertion/deletion genotypes of the angiotensin-converting enzyme gene has been associated with failure of antiarrhythmic drug therapy in AF (Darbar et al., 2007). GWAS studies have identified more than 30 genetic loci in association with $\mathrm{AF}$, suggesting previously unrecognized potential mechanisms of the disease (Bapat et al., 2018). For example, a recent GWAS study identified a novel AF locus comprising intronic and several highly correlated missense variants situated in the I-, A-, and M-bands of titin, which is the largest protein in humans and responsible for the passive elasticity of heart and skeletal muscle (Nielsen et al., 2018). This and other studies highlight the need to identify potential mechanisms whereby genetic risk loci act to increase the risk of AF during fetal heart development.

However, as more genes are screened, more AF patients are identified carrying multiple deleterious rare variants and/or combinations of rare and common variants in ion channel genes (Christophersen et al., 2017; Weng et al., 2017a; Nielsen et al., 2018). Such variants may differ in their functional expression as specific atrial substrates or conditions that can modify channel function and lead to AF (Mann et al., 2012). The latter complicates the use of specific antiarrhythmic drugs when attempting to associate genetic variants with potential therapeutic targets. Nevertheless, research efforts combining individual genetic profiles and clinical risk factors (Weng et al., 2018), along with atrial cell modeling (Mann et al., 2012), may help decipher the electrophysiological phenotype and the AF risk. Altogether, genetic information available highlights the fact that genotype may potentially enhance selection of 
patients most likely to benefit from new mechanismtargeting therapies and aid in future clinical studies.

\section{Pathophysiology of Atrial Fibrillation}

\section{A. Mechanisms of Atrial Fibrillation Initiation and Maintenance}

The mechanisms that maintain $\mathrm{AF}$ in the human heart have been and continue to be a matter of intense debate. Despite more than 100 years of research and speculation, we are yet to fully understand its fundamental mechanisms and learn how to treat it effectively. In the late 1950s the seminal work of Moe and Abildskov (1959) led to the multiple wavelet hypothesis, which posited that $\mathrm{AF}$ is maintained by multiple coexisting electrical wavelets that propagate randomly and uninterruptedly throughout the atria. Moe and Abildskov postulated also that there were important requirements to allow fibrillation to be self-sustained. One such requirement was that a minimum number of propagating wavelets must be simultaneously exciting a tissue volume, a hypothesis that seemed to fit well with the excellent results obtained subsequently by Cox et al. (1991) using the surgical MAZE procedure. Briefly, the procedure consists of surgically compartmentalizing the atrium in small segments so that the volume that accommodates the minimal number of wavelets is larger than the new volume in each compartment. Therefore, $\mathrm{AF}$ becomes unsustainable due to the high probability of wavelet annihilation because of collision with the new boundaries. However, even if its assumptions were correct, the multiple wavelet hypothesis leaves many unresolved questions, including: What mechanisms explain the focal activity, wavebreak formation, and reentry that usually occur during AF? How does the multiple wavelet hypothesis explain the hierarchical spatiotemporal organization that has been consistently demonstrated in animal models and humans over the last 20 years of research (Vaquero et al., 2008)? More importantly, how does the multiple wavelet hypothesis explain the often successful termination of AF by pulmonary vein isolation and other highly localized ablation procedures in a significant number of patients? Finally, from a clinical point of view, the idea of randomness of wave propagation during $\mathrm{AF}$ introduces large uncertainties when trying to design effective therapy approaches, because whenever any target is addressed the outcome would be unpredictable.

Today, two main deterministic theories attempt to explain the mechanisms that control the complex patterns of wave propagation in AF. On the one hand, some authors postulate that high-frequency activation during $\mathrm{AF}$ depends on a widespread endoepicardial electrical dissociation that promotes complex bidirectional conduction between the two layers of the atrial walls that behave functionally independently (de Groot et al., 2010). The emergent waves propagating from deeper layers break through each surface mimicking focal activity, whereas the dissociated propagation between endo- and epicardium promotes self-sustainment of the activity (de Groot et al., 2010, 2016). On the other hand, others support the theory of rotors, which gives predominance to a small number of localized functional reentrant sources (rotors) generating spiral waves (Jalife et al., 2002; Narayan et al., 2012). Such waves emerge at high frequency, propagating away from the rotor to interact with tissue heterogeneities and giving rise to complex patterns of nonuniform propagation termed "fibrillatory conduction" (Jalife et al., 2002). While rotors have been demonstrated in the atria of patients undergoing radiofrequency ablation (see Fig. 1), how both theories reconcile with the observed spatiotemporal organization during $\mathrm{AF}$ and whether they may even be combined to explain $\mathrm{AF}$ remains a matter of continuing debate (Allessie and de Groot, 2014; Narayan and Jalife, 2014). But the transcendent concept here is that randomness has lost its prominence as an explanation for $\mathrm{AF}$ maintenance, the research community now favoring singular mechanisms, which, although highly complex, are nevertheless consistent with the hierarchical organization of the atria during $\mathrm{AF}$ and potentially able to produce the necessary physical or pharmacologic tools to terminate AF more effectively (Calvo et al., 2017).

\section{B. Triggered Activity, Reentry, and the Initiation of Atrial Fibrillation}

Better agreement exists currently among clinicians and scientists regarding the mechanisms of AF initiation. Although the numerous in vivo and in vitro studies have not conclusively defined a mechanism, both triggered activity and reentry have been suggested. In 1998 Haïssaguerre et al. (1998) first demonstrated in human patients that the atrial sleeves in the pulmonary veins harbor the vast majority of the ectopic electric triggers that initiate AF. Since then, multiple researchers have confirmed Haïssaguerre's results and also identified additional ectopic trigger locations (e.g., the superior vena cava and the vein of Marshall) (Enriquez et al., 2017). With time, the procedure involving electrical isolation of the pulmonary veins $(\mathrm{PVs})$ revolutionized the field and became universally accepted as the gold standard to prevent AF initiation and maintenance. The outcomes of ablation procedures are consistent with both mechanisms. Substantial evidence emerged, also connecting PV ectopic triggers to the initiation of reentry in sustained AF. In a cholinergic model of AF, Klos et al. (2008) showed that the initiation of reentry and $\mathrm{AF}$ by impulses emanating from a PV is rate dependent. At critically high rates, propagation into the posterior wall of the left atrium becomes discontinuous, leading to conduction block and wavebreak formation with curling of the wave front around a pivoting "singularity point" that becomes the rotor that organizes the fibrillatory activity. Sustained functional reentry stabilizes as a single or a pair of 


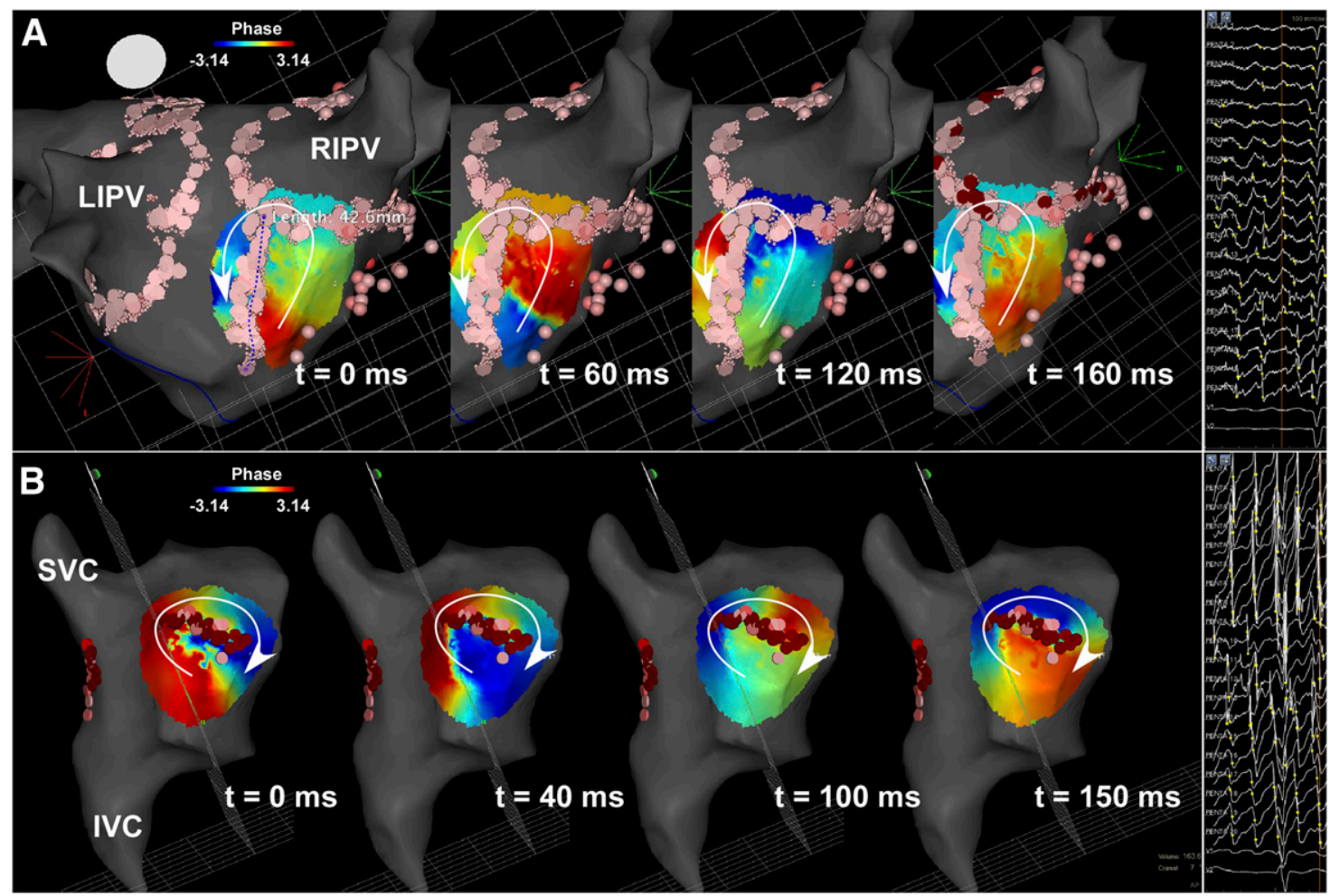

Fig. 1. Examples of rotor domains localized in human atria and their ablation. (A) A rotor domain, defined as an anatomic location displaying repetitive rotational activity organized by a meandering singularity point, is displayed at the floor of the left atrium. The ablation line (pink dots) crosses the distribution of the singularity points up to the right circumferential pulmonary vein isolation. (B) A rotor domain in the lateral wall of the right atrium. The ablation line (pink and red dots) crosses the distribution of the singularity points on the right atrium lateral wall. Corresponding unipolar recordings are displayed on the right hand side. IVC, inferior vena cava; LIPV, left inferior pulmonary vein; RIPV, right inferior pulmonary vein; SVC, superior vena cava. Reproduced with permission from Calvo et al. (2017).

counter-rotating "rotors" at or near the PV antrum, with centrifugal spiral wave activation to the rest of the atrium. The latter suggests that heterogeneities in the atrial substrate lead to dynamic interaction with highfrequency electrical inputs. Under critical conditions it would be possible to initiate functional reentry that will become the source of the first emanating wavelets. The preferential site for reentry formation would depend on the distribution of heterogeneities, moving away from the PV antrum as the substrate becomes more complex in the structurally affected atria (i.e., myocardial fibrosis) (Tanaka et al., 2007). Organization in the frequency domain of patients with AF seems to follow the same distribution. Patients with paroxysmal AF and no structural heart disease tend to display the highest frequency sites concentrated at or near the PV antrum, whereas patients with persistent AF, whose arrhythmogenic substrate is often more complex, display a more widespread distribution of highest frequencies that may be localized in either the left or the right atrium (Sanders et al., 2005; Atienza et al., 2014).

Topics of high relevance to AF initiation and maintenance are the histologic composition of the PV sleeves and the role of specific cell types in generating ectopic activity that triggers AF. As will be discussed below, atrial-like cardiomyocytes comprise most of the evidence. But some researchers call attention to additional cell types including nodal-like $\mathrm{P}$ cells, transitional cells, and large Purkinje-like myocytes, all of which have been suggested to participate in the architecture of the PVs of patients with a history of AF (Perez-Lugones et al., 2003). In addition, the role of the cardiac neural network has been gaining much attention during the last several years. Neuronal plexi surrounding the PVs may contribute to modulate electrophysiological properties of PV cells in a variety of ways, including through vagal influxes that shorten the APD and create conditions for high-frequency reentry (Arora, 2012; Wickramasinghe and Patel, 2013). An intriguing recent observation is the demonstration of interstitial cells of Cajal as a constitutive part of the architecture of the PVs in patients with a history of AF (Gherghiceanu et al., 2008; Morel et al., 2008). In the gastrointestinal system, the interstitial cells of Cajal are well known drivers of pacemaker activity promoting peristalsis. To what extend such cells may be the source of ectopic activity in humans remains under discussion. To the best of our knowledge, no studies have yet addressed the electrophysiology or the function of these interesting cells.

\section{Ionic Bases of Triggered Activity}

The pulmonary veins are a major source of ectopic electrical triggers (Haïssaguerre et al., 1998). When the triggered waves propagate into the left atrium they may 
break as they interact with the atrial tissue and engender the rotors that sustain AF (Kalifa et al., 2006; Klos et al., 2008). After the seminal work by Haïssaguerre et al. (1998) demonstrating the effectiveness of isolation of the PV in the treatment of paroxysmal $\mathrm{AF}$ in patients, many researchers have endeavored to understand why the atrial muscular sleeves penetrating the PV walls are arrhythmogenic. There is substantial agreement that the mechanism leading to $\mathrm{PV}$ discharges in animal models and patients with AF is mainly triggered activity, which is defined as cardiac impulse initiation that is dependent on afterdepolarizations (Cranefield and Aronson, 1988). Afterdepolarizations are oscillations in membrane potential that follow the upstroke of an action potential. The two kinds of afterdepolarizations known to cause triggered activity are early afterdepolarizations (EADs) and delayed afterdepolarizations (DADs). EADs occur early, i.e., during phase 2 or 3 of repolarization of the action potential, whereas DADs are delayed until repolarization is complete or nearly complete (Wit and Boyden, 2007). When an EAD or DAD is large enough to reach the threshold potential for activation of a regenerative inward current, a triggered action potential ensues. EAD- and DAD-induced triggered activity is always preceded by at least one action potential.

Although the evidence supporting triggered activity as an initiator of AF is not conclusive, special conditions of PV electrophysiology might facilitate EADs and DADs. Pulmonary vein muscle fibers have a smaller $\mathrm{I}_{\mathrm{K} 1}$ and thus less negative membrane potential and a slower phase-0 upstroke velocity than atrial muscle. This difference is more prominent in the distal than proximal veins (Hocini et al., 2002; Ehrlich et al., 2003; Wang et al., 2003). PVs also have shorter APD associated with larger delayed rectifier $\mathrm{K}^{+}$currents $\left(\mathrm{I}_{\mathrm{Kr}}\right.$ and $\mathrm{I}_{\mathrm{Ks}}$ ). To date only one study in the normal dog heart has described what has been interpreted as triggered activity, arising just proximal to the venous ostium in the presence of isoproterenol, with an increased rate after rapid pacing (Arora et al., 2003). However, a role for triggered activity is uncertain because no pacemaker potentials or afterdepolarizations were demonstrated. EAD-induced triggered activity is usually dependent on APD prolongation, with reactivation of inward $\mathrm{Ca}^{2+}$ or $\mathrm{Na}^{+}$current during the plateau phase (Fozzard, 1992). Studies using microelectrode recordings in tissue preparations have suggested, however, that simultaneous activation of cholinergic and adrenergic receptors, which reduces action potential duration, can result in triggered activity emerging from EADs during phase 3 of repolarization (Schauerte et al., 2001; Patterson et al., 2006). But these were in vitro conditions in which nonsustained reentry could not be ruled out. Therefore, although the autonomic nervous system may sometimes be involved in AF (Schauerte et al., 2001; Pappone et al., 2004), late phase $3 \mathrm{EAD}$-triggered activity caused by the above mechanisms remains to be demonstrated under physiologic conditions.

\section{Ion Channels and Reentry in Atrial Fibrillation}

The spatial distribution of ion channel functional expression is heterogeneous throughout the atria (Vaquero et al., 2008; Swartz et al., 2009; Voigt et al., 2010). In addition, the amount of remodeling ion channels undergo with time in AF is also heterogeneous (Nattel et al., 2007). Such heterogeneities are responsible for the different electrophysiological properties of different regions of the atria in terms of conduction velocity, APD, and refractory period, all of which condition the ability of each region to maintain sustained reentry at different frequencies in response to the remodeling process. A study using specimens of human atrium demonstrated that chronic $\mathrm{AF}$ reduces the transient $\mathrm{K}^{+}$outward current and the ultrarapid component of the delayed rectifier current $\left(\mathrm{I}_{\mathrm{Kur}}\right)$ (Caballero et al., 2010). In addition, the slow component of the delayed rectifier $\mathrm{K}^{+}$ current $\left(\mathrm{I}_{\mathrm{Ks}}\right)$ is increased, which results in significant APD abbreviation. Importantly, such changes were quantitatively different between right and left atria, which may explain the propensity of one atrium to sustain more stable reentry at a higher frequency than the other. Functional reentry is extremely sensitive to changes in the ionic currents with three main factors being the most affected: 1 ) the width of the wave front, 2) the size of the rotor core (i.e., excitable tissue that remains unexcited forming the pivoting center) and 3) the excitability and refractoriness of the tissue ahead of the wave front (Vaquero et al., 2008). Increasing potassium inward currents leads to shortening of the APD, which allows faster spin of the rotor because of increased net hyperpolarizing currents during phases 2 and 3 of the AP. The latter agrees well with two observations: first 1) the significantly higher dominant frequency in persistent than paroxysmal AF of animals (Martins et al., 2014) and human patients (Sanders et al., 2005), and 2) the increased atrial frequency of activation after adenosine infusion (Atienza et al., 2006). In the heart, adenosine interacts with the $\mathrm{A} 1$ receptor and the ACh-activated inward rectifying $\mathrm{K}^{+}$current $\left(\mathrm{I}_{\mathrm{KACh}}\right.$ ) via intracellular signaling through G-proteins, producing an increased net hyperpolarizing current during phases 2 and 3 of the action potential to shorten the APD (Sarmast et al., 2003).

Sustained AF leads to downregulation of the depolarizing $\mathrm{I}_{\mathrm{Na}}$ and calcium currents via reduced expression of the alpha subunit of the sodium channel $\left(\mathrm{Na}_{\mathrm{v}} 1.5\right)$ and the alpha subunit of the calcium current $\left(\mathrm{Ca}_{\mathrm{V}} 1.2\right)$, respectively (Martins et al., 2014). The latter changes work to slow the AF frequency by increasing the sinksource imbalance at the rotor core (Vaquero et al., 2008). However, unlike the inward currents, sustained AF results in an increased functional expression of the Kir2.1 channel (Martins et al., 2014), the molecular equivalent of the inward rectifier potassium current $\mathrm{I}_{\mathrm{K} 1}$, 
which would have the opposite effect. Together with $\mathrm{I}_{\mathrm{KACh}}, \mathrm{I}_{\mathrm{K} 1}$ governs the dynamics of functional reentry (Pandit and Jalife, 2013; Calvo et al., 2014). For example, $\mathrm{I}_{\mathrm{K} 1}$ elevation yields faster and more stable rotors because of both a greater outward conductance at the core and a shortened action potential duration in the core vicinity, as well as increased excitability, in part due to faster recovery of $\mathrm{I}_{\mathrm{Na}}$ (Samie et al., 2001; Noujaim et al., 2007). The latter should result in a larger rate of increase in the local conduction velocity as a function of the distance from the core in persistent compared with paroxysmal AF. In combination, these results strongly suggest that $\mathrm{I}_{\mathrm{K} 1}$ upregulation establishes a substrate for stable and very fast rotors (Noujaim et al., 2007). Of interest, the remodeling process also promotes an increase in $\mathrm{I}_{\mathrm{Ks}}$ and postrepolarization refractoriness, which facilitates wavebreak formation and spatially distributed complex patterns of fibrillatory conduction of the wave fronts emanating at high rate from the core (Muñoz et al., 2007).

\section{Status of Antiarrhythmic Drugs in Atrial Fibrillation}

\section{A. Atrial Selective Ion Channel Blockers}

During the last decade, drug interaction with ion channels that are selectively expressed in the atria emerged as a promising therapy able to control AF without significant consequences to the electrophysiology of the ventricles (Ehrlich et al., 2008). The spectrum of targets spans from the ultrarapid delayed rectifier $\mathrm{K}^{+}$ current ( $\mathrm{I}_{\text {Kur }}$ ) (Walsh, 2015) and the constitutively active acetylcholine (ACh)-activated $\mathrm{K}^{+}$current $\left(\mathrm{I}_{\mathrm{KACh}}\right.$ ) (Dobrev et al., 2005) to newly proposed mechanisms like atrial-selective $\mathrm{Na}^{+}$channel inhibition (Burashnikov et al., 2012) and interaction with the small-conductance $\mathrm{Ca}^{2+}$-activated $\mathrm{K}^{+}$(SK) channels (Diness et al., 2010), the two-pore $\mathrm{K}^{+}\left(\mathrm{K}_{2 \mathrm{P}}\right)$ channels (Schmidt et al., 2017a), and the stretch-activated channels (SAC) (Franz and Bode, 2003) (Visual Abstract and Table 1).

$\mathrm{I}_{\text {Kur }}$ is a transient outward current that rapidly inactivates, leaving a sustained outward current after continued depolarization (Wang et al., 1993). $\mathrm{I}_{\mathrm{Kur}}$ is present only in the atria, but some $\mathrm{I}_{\mathrm{Kur}}$ blockers have minor unspecific effects in the ventricles. Several drugs have demonstrated that efficient $\mathrm{I}_{\mathrm{Kur}}$ inhibition promotes $\mathrm{AF}$ termination and precludes reinduction with some differences between them (Linz et al., 2007) (Blaauw et al., 2004; Stump et al., 2005). But the relevance of $I_{\text {Kur }}$ as an antifibrillatory target has been brought into question by the fact that a highly selective $\mathrm{I}_{\text {Kur }}$ blocking agent was ineffective in prolonging atrial refractory periods during sinus rhythm (Pavri et al., 2012) and also because $I_{K u r}$ is downregulated in the human atria during persistent AF (Caballero et al., 2010). However, it has been proposed that because of its atrial selectivity, $I_{K u r}$ blockade might contribute to optimize the anti-AF effects of $\mathrm{Na}^{+}$-channel blockers
(Aguilar et al., 2015). Thus, in the future, the combined therapy might more efficiently control $\mathrm{AF}$, provided drug development works to overcome the substantial adverse effects of $\mathrm{I}_{\mathrm{Na}}$ blockers that have been demonstrated in diverse clinical scenarios (Echt et al., 1991).

Although the voltage dependence of inactivation or blockade of $\mathrm{I}_{\mathrm{Na}}$ seems quite similar in human atrial and ventricular cardiomyocytes (Furukawa et al., 1995), differences in the AP configuration between both cell types may explain atrial selectivity of some $\mathrm{I}_{\mathrm{Na}}$ blockers (Hancox et al., 2016). Ranolazine is an open-state blocker that becomes trapped in the inactivated state (Zygmunt et al., 2011), which together with the fact that in atrial cells the $\mathrm{Na}^{+}$channel spends more time in the inactivated state than the ventricles explains atrial selectivity. Some experimental studies demonstrated significant effects on AF physiology, leading to reduced frequency of fibrillatory waves and AF termination (Black-Maier et al., 2017). But there is controversy regarding the role of ranolazine in the treatment of human $\mathrm{AF}$, with recent studies demonstrating just borderline effects in terms of clinical efficacy (De Ferrari et al., 2015).

Wenxin Keli (WK) is a Chinese herb extract that includes five main components: Nardostachys chinensis batal extract, codonopsis, notoginseng, amber, and Rhizoma polygonati (Xue et al., 2013). WK appears to exert atrial selective inhibition of $\mathrm{I}_{\mathrm{Na}}$ because of differences in AP configuration in atria versus ventricles, i.e., the atria have a more negative steady-state inactivation, a less negative resting membrane potential, and shorter diastolic intervals than the ventricles (Burashnikov et al., 2007). Consequently, the drug effectively suppresses AF in experimental models ( $\mathrm{Hu}$ et al., 2016). WK has been tested in limited clinical scenarios, like $\mathrm{AF}$ associated with hyperthyroidism, in which WK seems to as efficacious as sotalol in preventing AF perpetuation (Meng et al., 2015). However, the clinical information is very limited (Chen et al., 2013), and further evidence is needed before its use may be generalized.

The small-conductance $\mathrm{Ca}^{2+}$-activated $\mathrm{K}^{+}(\mathrm{SK})$ channels contribute to repolarization in atrial cardiomyocytes during the latter phase of the action potential, an effect that seems larger than in the ventricles (Xu et al., 2003). In experimental models, upregulation of SK channels leads to APD shortening after rapid atrial pacing and promotes atrial arrhythmias (Tsai et al., 2016). Recently, the SK channel inhibitor AP14145 was shown to be effective in controlling AF resistant to vernakalant in pigs (Diness et al., 2017). However, there is evidence of downregulation of SK channels during human $\mathrm{AF}$ (Yu et al., 2012) and no indication of an effect on the atrial APD of patients with AF (Skibsbye et al., 2014), which raises substantial doubt about the role of SK blockers in the treatment of human AF. In addition, there is concern regarding possible proarrhythmia, which might limit the translation to clinical testing of 
TABLE 1

Some characteristics of antiarrhythmic drugs that show atrial specificity

\begin{tabular}{|c|c|c|}
\hline Blocker or Modulator (Drug) & Target & Comments \\
\hline BMS914392 & $I_{K A C h}$ & $\begin{array}{l}\text { Resulted ineffective in clinical studies } \\
\text { Potential adverse/vagolytic effects }\end{array}$ \\
\hline MK-0448 & $I_{\text {Kur }}$ & Appears ineffective \\
\hline $\mathrm{I}_{\mathrm{Na}}$ Blockers & $I_{N a}$ & $\begin{array}{l}\text { Ranolazine resulted ineffective in clinical studies } \\
\text { Wenxin-Keli appears effective but needs additional } \\
\text { studies }\end{array}$ \\
\hline Multichannel blockers & $\begin{array}{l}I_{N a} \\
I_{K u r}\end{array}$ & $\begin{array}{l}\text { Celivarone resulted ineffective in clinical studies } \\
\text { Budiodarone appears effective but need for additional } \\
\text { studies }\end{array}$ \\
\hline & $\begin{array}{c}I_{K A C h} \\
I_{K r} \\
I_{K s}\end{array}$ & $\begin{array}{l}\text { Vernakalant seems effective for acute conversion to } \\
\text { sinus rhythm }\end{array}$ \\
\hline AP14145: & $S K$ & $\begin{array}{l}\text { SK channels are downregulated in human AF } \\
\text { No effect on APD of patients with AF }\end{array}$ \\
\hline SAC Blockers & $S A C$ & $\begin{array}{l}\text { Gadolinium is effective in experiments } \\
\text { Selective agents have not been tested in the clinic }\end{array}$ \\
\hline $\mathrm{K}_{2 \mathrm{p}}$ Blockers & $K_{2 p}$ & $\begin{array}{l}\text { Amiodarone and Dronedarone } \\
\text { Selective analogs are under development but have not } \\
\text { been tested in the clinic }\end{array}$ \\
\hline IP3 modulators & IP3 Receptor & $\begin{array}{l}\text { Not clinically tested as yet } \\
\text { Potential systemic effects due to nonspecificity }\end{array}$ \\
\hline Dantrolene & $R y R 2$ & $\begin{array}{l}\text { Not clinically tested in } \mathrm{AF} \text { as yet } \\
\text { Potential hepatotoxicity on chronic oral administration }\end{array}$ \\
\hline Rotigaptide & Connexin & $\begin{array}{l}\text { Not clinically tested as yet } \\
\text { Improvement of conduction velocity does not correlate } \\
\text { with AF vulnerability }\end{array}$ \\
\hline
\end{tabular}

drugs blocking SK channels (Hsueh et al., 2013; Hancock et al., 2015). The two-pore $\mathrm{K}^{+}\left(\mathrm{K}_{2 \mathrm{P}}\right)$ channels are responsible for background currents in human atrial cardiomyocytes, and in patients with chronic $\mathrm{AF}$ some isoforms (e.g., $\mathrm{K}_{2 \mathrm{P}} 3.1$ ) are upregulated and thought to contribute to APD shortening (Schmidt et al., 2015). The pharmacology of $\mathrm{K}_{2 \mathrm{P}}$ channels has been gaining attention over the last 10 years; the interested reader may find extensive reviews in the relevant literature (Ravens and Wettwer, 2011; Hancox et al., 2016). Notably, commonly used antiarrhythmic drugs such as amiodarone (Gierten et al., 2010) and dronedarone (Schmidt et al., 2012) block $\mathrm{K}_{2 \mathrm{P}} 3.1$ channels. Yet selective agents are still under development and have not been tested in the clinic (Flaherty et al., 2014).

The stretch-activated nonselective cation channels (SACs; permeable to $\mathrm{Na}^{+}, \mathrm{Ca}^{2+}$, and $\mathrm{K}^{+}$) are another group of channels whose molecular structure is still not entirely known but whose functional behavior has been well-characterized (Riemer et al., 1998). SACs inhibition by the GsMTx4 peptide (a tarantula spider venom toxin) suppresses AF in experimental models (Bode et al., 2001). In addition, atrial stretch correlates with shortened APD and refractoriness promoting AF (Ravelli and Allessie, 1997). By blocking SACs (Chang et al., 2007), gadolinium reduces AF vulnerability in a dosedependent manner (Bode et al., 2000) and decreases spontaneous firing from the pulmonary veins in animal models. However, selectivity has not been demonstrated, because SACs are also functionally active in the ventricles and modulate susceptibility to ventricular fibrillation (Barrabés et al., 2013; Calvo and Jalife, 2013).
Interestingly, some $\mathrm{K}_{2 \mathrm{P}}$ channel isoforms exhibit mechanosensitive responses (Schmidt et al., 2017a), which adds to the complexity in the role of stretch in the pathophysiology of AF (Ninio and Saint, 2008; Yamazaki et al., 2009). The mechanosensitive isoform $K_{2} 2.1$ is downregulated, whereas the $\mathrm{K}_{2 \mathrm{P}} 10.1$ isoform is upregulated in AF, which might contribute to APD changes in patients with concomitant heart failure (Schmidt et al., 2017a). In addition, $\mathrm{K}_{2 \mathrm{P}} 3.1$ is upregulated in patients with severe systolic dysfunction and chronic $\mathrm{AF}$ but not in patients in sinus rhythm (Schmidt et al., 2017b). However, further investigation is needed to confirm a significant role of mechanosensitive $\mathrm{K}_{2 \mathrm{P}}$ channels in human atrial physiology and AF pathophysiology. In addition, translation to clinical testing is also limited by the fact that specific inhibitors of mechanosensitive $\mathrm{K}_{2 \mathrm{P}}$ channels are currently not available.

\section{B. Acetylcholine-Activated Inward Rectifying $\mathrm{K}^{+}$ Current and Atrial Fibrillation}

Vagal control of the heart is mediated in part via the inwardly rectifier potassium acetylcholine activated channel responsible for $\mathrm{I}_{\mathrm{KACh}}$, which is constitutively upregulated during AF (Cha et al., 2006) and promotes sustained $\mathrm{AF}$ in the absence of cholinergic mediators (Kovoor et al., 2001; Klos et al., 2008). Acetylcholine activates $\mathrm{I}_{\mathrm{KACh}}$ via its interaction with $\mathrm{M} 2$ receptors and intracellular G-protein transducers (see Visual Abstract), promoting APD shortening and AF maintenance. In humans and animal models, $\mathrm{I}_{\mathrm{KACh}}$ activation via adenosine infusion significantly shortens APD (Sarmast et al., 2003) and increases the dominant frequency at anatomic 
regions believed to contain the AF drivers (Atienza et al., 2006). On the contrary, $I_{K A C h}$ blockade significantly prolongs $\mathrm{APD}$ and atrial refractoriness, leading to $\mathrm{AF}$ termination in animal models (Cha et al., 2006). Commonly used antiarrhythmics like dronedarone and ibutilide nonspecifically block $\mathrm{I}_{\mathrm{KACh}}$, which explains in part their antifibrillatory properties (Ravens et al., 2013). However, development of selective $\mathrm{I}_{\mathrm{KACh}}$ blockers for $\mathrm{AF}$ treatment in humans will require avoiding molecules with significant vagolytic adverse effects at therapeutic doses. Recently, BMS914392, a potent and selective oral inhibitor of $\mathrm{I}_{\mathrm{KACh}}$ has been tested in the clinic (Podd et al., 2016). BMS914392 failed to maintain sinus rhythm in patients with paroxysmal AF when administered at the doses required to avoid neurologic adverse effects. Other molecules have been evaluated experimentally with favorable results (Kockskämper et al., 2008; Machida et al., 2011), but to the best of our knowledge they have not been clinically tested.

\section{Multichannel Blockade Drugs that Minimize Adverse Events}

Multichannel-blockade drug therapy derives from the well-known antiarrhythmic efficacy of amiodarone, which may be considered the most effective drug preventing $A F$ recurrences, although it is also very effective in terminating AF (Lip et al., 2012). However, the significant extra cardiac adverse actions of amiodarone are also very well-known and substantially limit its clinical use (Singh, 2008).

Dronedarone was derived from the molecular structure of amiodarone, attempting to minimize its toxicity (Doggrell and Hancox, 2004). Dronedarone does not contain the iodine moieties of amiodarone, which has substantially less toxic effects on the thyroid and other organs. Dronedarone's electrophysiological profile is similar to amiodarone, although it has been shown to be a 10 times more potent blocker of the sodium current in human atrial myocytes and up to 100 times more potent as a blocker of $\mathrm{I}_{\mathrm{KACh}}$ in guinea pig atrial myocytes (Guillemare et al., 2000; Lalevée et al., 2003). Yet, despite its promising profile, dronedarone shows a very limited ability to terminate $\mathrm{AF}$ in both experiments and the clinic (Burashnikov et al., 2010; Le Heuzey et al., 2010). The different clinical outcomes of amiodarone and dronedarone in the treatment of $\mathrm{AF}$ remain unexplained. However, it might be related to the fact that the active metabolite of amiodarone ( $N$-desethylamiodarone) accumulates in cardiac tissue (Holt et al., 1983), whereas dronedarone's active metabolite ( $N$-debutyldronedarone) does not accumulate. Indeed, the antiarrhythmic effects of $N$-desethylamiodarone are presumably superior to $N$ debutyldronedarone (Talajic et al., 1987). Amiodarone's interaction with thyroid hormone, which depends on the iodide moieties that are absent in dronedarone, may also contribute to amiodarone's antiarrhythmic properties. Finally, it is important that dronedarone is contraindicated in patients with $\mathrm{HF}$ and New York Heart Association functional class III-IV after the report of the prematurely terminated ANDROMEDA trial, which showed an increase in mortality in the dronedarone group compared with placebo (Køber et al., 2008).

Celivarone is a noniodinated benzofuran derivative that is pharmacologically related to dronedarone and amiodarone. Celivarone blocks $\mathrm{I}_{\mathrm{Kr}}, \mathrm{I}_{\mathrm{Ks}}, \mathrm{I}_{\mathrm{KACh}}, \mathrm{I}_{\mathrm{Kur}}$, and $\mathrm{I}_{\mathrm{CaL}}$ (Gautier et al., 2004). It also inhibits $\beta 1$-adrenoceptormediated increases in heart rate and $\alpha$-adrenoceptor and angiotensin-II-mediated increases in blood pressure. Interestingly, celivarone has been reported to be as potent as dronedarone and approximately threefold more effective than amiodarone in restoring sinus rhythm in vagally induced AF in dogs (Gautier et al., 2005). However, the drug failed to show efficacy preventing $\mathrm{AF}$ recurrences and terminating $\mathrm{AF}$ in the clinic (Khitri et al., 2012).

Budiodarone is another chemical analog of amiodarone with similar multichannel blocking properties (Arya et al., 2009). Unlike amiodarone, budiodarone undergoes rapid metabolism by plasma and tissue esterases, which potentially makes it less susceptible to drug-drug interactions with drugs that inhibit CYP450-mediated metabolism (Juhász and Bodor, 2000). A preliminary randomized trial in patients with paroxysmal $\mathrm{AF}$ and dual-chamber pacemaker devices (capable of storing and quantifying $\mathrm{AF}$ burden) reported that budiodarone significantly reduced $\mathrm{AF}$ and atrial flutter burden after 12 weeks of treatment compared with placebo (Ezekowitz et al., 2012).

Despite enormous difficulties in the development of new antiarrhythmic drugs that have a multichannel blockade profile but lack extracardiac adverse effects, the broad cardiac safety profile of amiodarone and its strong antiarrhythmic effects are encouraging investigators and industry to continue developing similar molecules. Over the last several years, vernakalant, a multichannel blocker with relatively selective effects on $\mathrm{I}_{\mathrm{Kur}}$, some blocking actions on $\mathrm{I}_{\mathrm{KACh}}$ and $\mathrm{I}_{\mathrm{Na}}$, and minor effects on other ionic channels at therapeutic concentrations (Dorian et al., 2007), has demonstrated successful in acutely converting AF to sinus rhythm when administered intravenously (Camm et al., 2011). It has also been tested orally for the prevention of AF recurrences postcardioversion, with modest efficacy when compared with placebo (Torp-Pedersen et al., 2011). Nevertheless, the good safety profile displayed by vernakalant has motivated additional studies toward developing new molecules with a similar profile.

\section{New Drug Uses and New Molecular Mechanisms}

\section{A. Targeting Inward-Rectifying $\mathrm{K}^{+}$Channels, Insights from Chloroquine Use in Experimental Atrial Fibrillation}

Inwardly rectifying $\mathrm{K}^{+}$currents $\left(\mathrm{I}_{\mathrm{K} 1}, \mathrm{I}_{\mathrm{KACh}}\right.$, and $\left.\mathrm{I}_{\mathrm{K}-\mathrm{ATP}}\right)$ play important roles in controlling rotor dynamics 
and stabilizing fast reentrant activity (Pandit and Jalife, 2013). Although $\mathrm{I}_{\mathrm{K}-\mathrm{ATP}}$ is prominent in ischemia (Noma, 1983) and $\mathrm{I}_{\mathrm{KACh}}$ underlies vagally mediated reentry in paroxysmal AF (Noujaim et al., 2010), $\mathrm{I}_{\mathrm{K} 1}$ is the most relevant inwardly rectifying $\mathrm{K}^{+}$current controlling cardiac fibrillation. In fact, both specific and preferential $\mathrm{I}_{\mathrm{K} 1}$ blockade have consistently been shown to terminate cardiac fibrillation in different experimental models, including both AF and ventricular fibrillation (Warren et al., 2003; Noujaim et al., 2007, 2010; Filgueiras-Rama et al., 2012). Although attractive, $\mathrm{I}_{\mathrm{K} 1^{-}}$ blockade is currently not used to treat patients with $\mathrm{AF}$, because to our knowledge, none of the antiarrhythmic drugs available to date block $\mathrm{I}_{\mathrm{K} 1}$ specifically at therapeutic concentrations. In addition, the fear that reducing $\mathrm{I}_{\mathrm{K} 1}$ would reduce the resting membrane potential during diastole and consequently increase propensity for triggered arrhythmias likely limits chloroquine's appeal. Interestingly, based on the expression profile of the Kir2.x subfamily of inwardly rectifying $\mathrm{K}^{+}$channels, Kir2.3 transcripts are mostly concentrated in the human atria rather than the ventricles (Schram et al., 2002). Protein crystallization, molecular modeling, and interactions with modulators (e.g., Phosphatidylinositol 4,5bisphosphate or PtdIns(4,5)P2, PIP2) (Du et al., 2004) might lead to new pharmacological strategies focusing on selective blockade of Kir2.3 subunits. The latter becomes especially relevant in the setting of congestive $\mathrm{HF}$, in which $\mathrm{I}_{\mathrm{K} 1}$ downregulation might be associated with increased susceptibility to ventricular arrhythmias (Pogwizd et al., 2001).

The potential impact of developing clinically relevant atrial-specific $\mathrm{I}_{\mathrm{k} 1}$ blockers has been highlighted by the use of chloroquine, an antimalarial quinolone, which as a relatively selective $I_{K 1}$ blocker has been shown to be highly effective in terminating $\mathrm{AF}$ in various experimental models (Noujaim et al., 2010; Filgueiras-Rama et al., 2012; Takemoto et al., 2018). At the structural level, the molecule interacts with electronegative residues (amino acids F254, D259, and E224) in the inner vestibule of the intracellular domains of Kir2.1 (Pegan et al., 2005; Noujaim et al., 2010). Such interactions cause a disruption of the channel upon chloroquine binding, which leads to a break in the ion permeation pathway (Noujaim et al., 2011). Chloroquine also interacts with negatively charged residues within the ion permeation pathway of the intracellular domain of Kir3.1 and Kir6.2, the channels responsible for the $\mathrm{I}_{\mathrm{KACh}}$ and $\mathrm{I}_{\mathrm{K}-\mathrm{ATP}}$, respectively, which likely provides additional synergistic antiarrhythmic properties. Although chloroquine blockade of Kir3.1 is similar to Kir2.3 through interaction with amino acids D260 and F255 in the ion-permeation pathway (Fig. 2) (Takemoto et al., 2018), the lack of D259 and E224 in Kir6.2 and its substitution for neutral polar residues leads to a decrease in chloroquine's ability to block the channel (Noujaim et al., 2010). Beyond the specific molecular interactions, chloroquine blockade of the inward rectifying $\mathrm{K}^{+}$channels may partially explain the drug's antiarrhythmic power in such pathophysiological scenarios as vagally mediated $\mathrm{AF}$ or persistent $\mathrm{AF}$ in the presence of constitutively active $\mathrm{I}_{\mathrm{KACh}}$ and $\mathrm{I}_{\mathrm{K} 1}$ increase (Noujaim et al., 2010; Makary et al., 2011; Martins et al., 2014; Takemoto et al., 2018). Chloroquine's ability to terminate persistent $\mathrm{AF}$ in Langendorff-perfused hearts explanted from a clinically relevant sheep model is remarkable (Filgueiras-Rama et al., 2012; Takemoto et al., 2018). It supports the concept that combined $\mathrm{I}_{\mathrm{K} 1}$ and $\mathrm{I}_{\mathrm{KACh}}$ blockade may be synergistic and play a crucial role in terminating persistent $\mathrm{AF}$; although chloroquine terminated $100 \%$ of the $\mathrm{AF}$ episodes, selective blockade of constitutively active $\mathrm{I}_{\mathrm{KACh}}$ by tertiapinQ (Ramu et al., 2004) failed to terminate $\mathrm{AF}$ in one-third of episodes. Moreover, the effects of chloroquine on the dynamics of AF occurred more rapidly than those of tertiapinQ (Takemoto et al., 2018).

There is limited but significant evidence for chloroquine's ability to terminate AF in the clinical setting. In a study of 64 patients with arrhythmias published 60 years ago in the New England Journal of Medicine (Burrell and Martinez, 1958), 31 patients had AF and were treated with chloroquine, 18 of these patients with AF responded favorably with restoration of sinus rhythm. The dosages of chloroquine used in that study were welltolerated, despite being considerably greater than those recommended at the time for other indications (Burrell and Martinez, 1958). However, chronic chloroquine administration is not free of systemic effects (AlKadi, 2007). Nevertheless, the foregoing suggests that revisiting chloroquine and its analogs as a starting point toward the development of a new generation of drugs capable of selectively blocking inward rectifying $\mathrm{K}^{+}$channels might be an interesting opportunity for pharma and for AF therapy.

\section{B. Intracellular $\mathrm{Ca}^{2+}$ Regulation as a Target for Atrial Fibrillation Therapy}

$\mathrm{Ca}^{2+}$ regulation is a major determinant of cellular electrophysiology in the heart, with some differences between atria and ventricles, which might result in a certain degree of drug selectivity. In the atria, inositol 1,4,5-triphosphate (IP3) receptor (IP3R) signaling is more developed (Kockskämper et al., 2008), and atrial cells display a much less developed T-tubule system than the ventricles. Consequently, in contrast with the ventricles, the most prominent calcium waves are observed at the subsarcolemma of atrial cardiomyocytes (Sheehan and Blatter, 2003). Interestingly, IP3R colocalizes with the cardiac ryanodine receptor (RyR2) at the subsarcolemma of atrial cardiomyocytes (Visual Abstract). The latter suggests the possibility that IP3R modulates RyR2 and $\mathrm{Ca}^{2+}$ release in some animal models (Mackenzie et al., 2002) and also in the human atria (Liang et al., 2009) and may explain the $\mathrm{Ca}^{2+}$ sparks leading to triggered activity under various pathologic conditions (Opel et al., 2015). The intracellular concentration of IP3 increases after activation of 
A

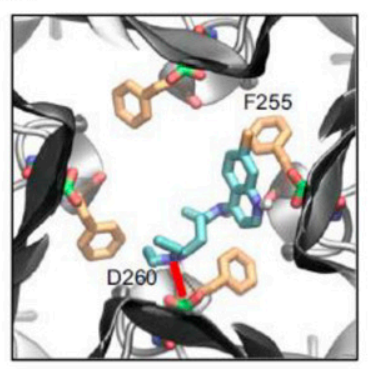

B

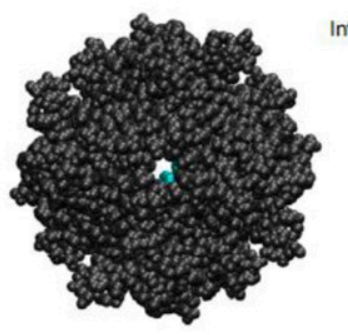

Intracellular

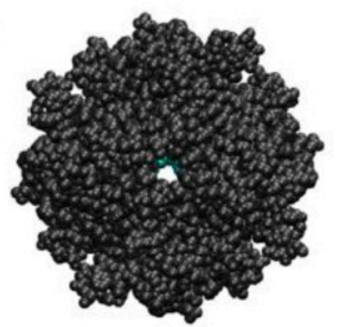

Extracellular
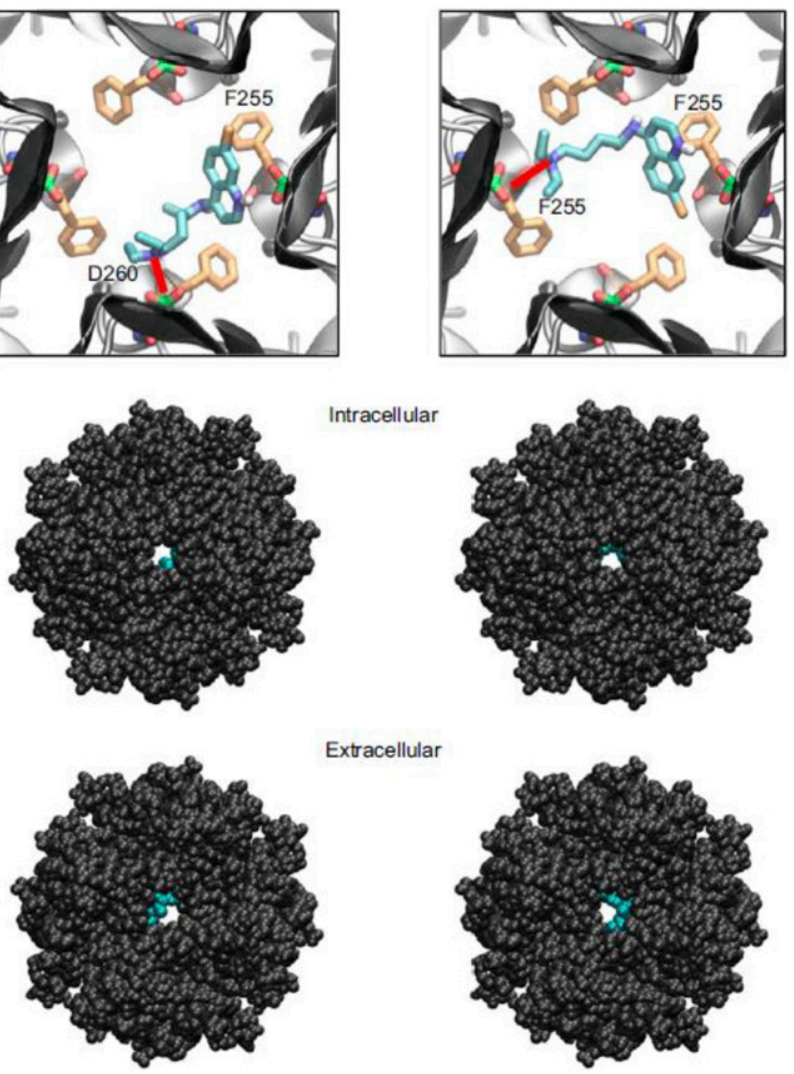

c

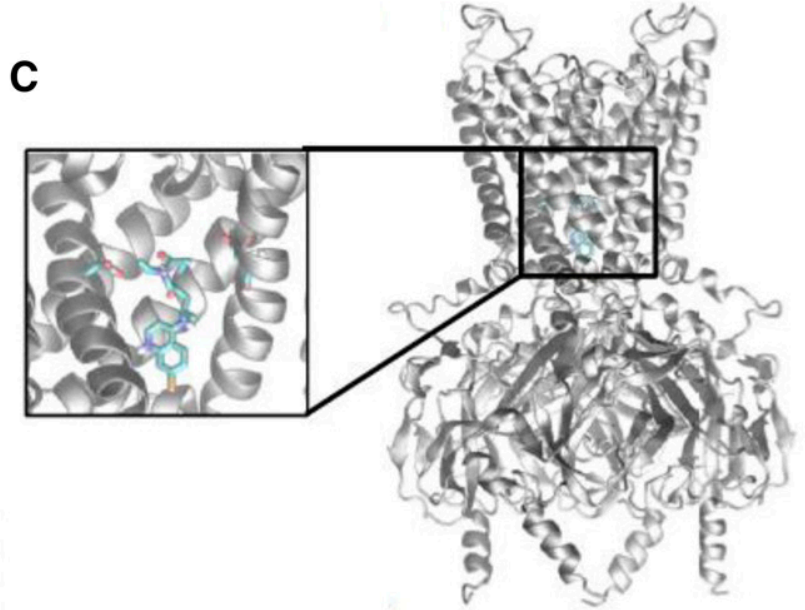

Fig. 2. Docking of chloroquine in the ion permeation pathway of the Kir3.1 channel. (A and B) Two lowest energy poses. Top: Magnified view of the binding poses of chloroquine (cyan sticks) in Kir3.1. The D260 and F255 residues from each of the 4 Kir3.1 subunits are shown in green and orange sticks, respectively. (A) The amine nitrogen of chloroquine forms a hydrogen bond (red line) with the side-chain of D260 in 1 subunit, whereas the aminoquinoline ring of chloroquine is involved in an aromatic-aromatic interaction with the phenylalanine ring of F255 in the adjacent subunit. (B) The amine nitrogen of chloroquine hydrogen bonds (red line) the carbonyl oxygen of F255 in 1 subunit, whereas the aminoquinoline ring of chloroquine is involved in an aromatic-aromatic interaction with the phenylalanine ring of F255 in the opposing subunit. Middle, bottom: van der Waals representations of the channel bound to chloroquine (cyan), viewed from the intracellular and extracellular sides, respectively. (C) Computational model of chloroquine docking in the aqueous region of the transmembrane domain in the homology model for Kir3.1 using the PDB of Kir3.2 (PDB ID: 3SYO). Chloroquine (in cyan) binds the transmembrane domain of the channel at residue. Modified with permission from figures 4 and 9 of Takemoto et al. (2018).

G-proteins via different membrane receptors; i.e., the muscarinic (M3) receptor, the endothelin-1 receptor ET-A, the angiotensin II receptor AT-I, and the $\alpha 1$ adrenergic receptor (Tinker et al., 2016). IP3R activation in turn increases RyR2 permeability, promoting $\mathrm{Ca}^{2+}$ sparks and triggered activity. Some regulators of G-protein signaling accelerate the intrinsic GTPase activity and deactivate G-protein-mediated signaling, which in turn decreases the intracellular concentration of IP3. Recently, global deletion of the regulator of G-protein signaling 4 in the mouse resulted in a higher rate of $\mathrm{AF}$ inducibility in addition to abnormal $\mathrm{Ca}^{2+}$ release in atrial cardiomyocytes even under basal conditions (Opel et al., 2015). It was therefore suggested that modulating the G-protein-IP3-Ca ${ }^{2+}$ signaling axis may be a potential target for treating AF. However, there are doubts about selectivity, because the axis is functionally active in many cellular processes and cell types, leading to potential adverse events in the heart and other organs. To our knowledge, no drug that modulates the G-protein-IP3-Ca ${ }^{2+}$ signaling axis has been tested for $\mathrm{AF}$ treatment in humans.
Altered RyR2 kinetics and downregulation of the L-type calcium current, both already occurring during atrial remodeling in $\mathrm{AF}$, contribute to abnormal $\mathrm{Ca}^{2+}$ handling and APD alternans and may facilitate triggered activity and wavebreak formation (Chang et al., 2014). Dantrolene increases the threshold for spontaneous $\mathrm{Ca}^{2+}$ release, decreasing $\mathrm{Ca}^{2+}$ leak from RyR2 (see Visual Abstract) (Jung et al., 2012). At clinically applicable and well-tolerated doses in humans, dantrolene effectively decreases the frequency of $\mathrm{Ca}^{2+}$ waves and the spontaneous $\mathrm{Ca}^{2+}$ transients and suppresses triggered activity in human atrial cells (Hartmann et al., 2017). Therefore, dantrolene is emerging as a potential drug able to control AF initiation. Recently, simulation studies suggested that RyR2 altered kinetics may also be crucial in underlying the complex behavior of functional reentry during $\mathrm{AF}$ and in governing of the transition from stable reentrant sources to an unstable and short-lasting multispiral state promoting wavelet formation (Chang and Trayanova, 2016). However, to the best of our knowledge there are yet no clinical data confirming a potential role for dantrolene in preventing 
AF or modulating physiologic conditions that promote $\mathrm{AF}$ termination in patients.

\section{Gap-Junction Therapy Aiming at Homogenous Impulse Propagation}

Consistently, atrial heterogeneity and slow conduction are common factors underlying $\mathrm{AF}$ initiation and maintenance (Jalife, 2011). Gap-junctions, comprised of proteins called connexins, connect myocardial cells to each other through low-resistance pathways. Therefore, connexin dysfunction may potentially lead to AF. More specifically, $\mathrm{Cx} 40$ may be the most relevant target for therapy among the connexin family, because it is abundantly expressed in the atria but not the ventricles (Gros et al., 1994). A relatively new group of antiarrhythmic agents classified as antiarrhythmic peptides improve gap-junctional conductance. Of these, rotigaptide has been shown to improve conduction velocity in several animal models (Haugan et al., 2006; Shiroshita-Takeshita et al., 2007), which did not always correlate with a decrease in $\mathrm{AF}$ duration or vulnerability (Shiroshita-Takeshita et al., 2007). Similar results have been obtained with other antiarrhythmic peptides (e.g., GAP-134) (Rossman et al., 2009). Yet to date it is unknown whether this strategy might be clinically relevant.

Even though the rationale behind the antiarrhythmic peptides seems potentially beneficial in $\mathrm{AF}$, the effects may not be homogeneous throughout the atria. This would not only enhance intrinsic atrial electrophysiological heterogeneities, but together with fibrosis and ion channel remodeling may counterbalance any potential benefits. An alternative to drug therapy may be the use of gene transfer to deliver $\mathrm{Cx} 43$ to the atrial tissue. Two different strategies using injection/electroporation or atrial painting of adenoviruses encoding $\mathrm{Cx} 43$ or $\mathrm{Cx} 40$ have been reported in a porcine model of AF based on rapid atrial pacing (Bikou et al., 2011; Igarashi et al., 2012). Both reports showed that AF could be prevented for a short-term period using such strategies.

\section{Novel Targets in Atrial Fibrillation}

\section{A. Ion Channels, Electrical Remodeling, and the Progression of Atrial Fibrillation}

AF frequently starts as paroxysmal AF, with spontaneous termination often occurring within 48 hours. Some patients suffer paroxysmal AF episodes indefinitely, but a significant number $(\approx 40 \%)$ progress to persistent $\mathrm{AF}$ within 10 years follow up (Padfield et al., 2017). AF-mediated remodeling involves changes at the structural, ionic, and mechanical levels that favor the initiation, maintenance, and perpetuation of $\mathrm{AF}$ (Nattel and Harada, 2014; Jalife and Kaur, 2015). Electrical remodeling, manifested by shortening of the atrial APD and refractoriness and loss of APD adaptation to changes in frequency, is known to develop within the first few days of AF (Allessie et al., 2002; de Vos et al., 2010) and to contribute to progressive prolongation of the duration of
AF episodes ("AF begets AF") (Wijffels et al., 1995). Several ion channel modifications underlying such electrical changes have been described in animal models and humans (Van Wagoner et al., 1999; Nattel et al., 2008; Caballero et al., 2010; Voigt et al., 2010; Heijman et al., 2014). However, until recently, the sequence and the way such changes integrate to perpetuate $\mathrm{AF}$ had not been elucidated, particularly in humans. Structural remodeling at the cell and tissue levels also contributes to intra-atrial conduction disturbances and increase susceptibility for AF, yet its role in progression from paroxysmal to persistent AF remains unknown. Finally, atrial mechanical function is significantly altered, with reduced contractility and electromechanical dissociation. Recent studies using a clinically relevant ovine model showed that during intermittent right atrial tachypacing, not only the duration of $\mathrm{AF}$ episodes increased as expected, but also the dominant excitation frequency (DF) increased gradually during a 2 -week period in both left and right atria, until it stabilized at a time that coincides with the onset of persistent AF (Martins et al., 2014). Thereafter, the DF remained stable during a 12-month follow up. Both the increases in the AF episode duration and the concomitant DF acceleration were associated with $\mathrm{I}_{\mathrm{CaL}}$ and $\mathrm{I}_{\mathrm{Na}}$ downregulation, and $\mathrm{I}_{\mathrm{K} 1}$ upregulation, along with corresponding changes in gene expression and ion-channel protein subunits. Structural remodeling in the form of cellular hypertrophy, atrial dilatation, and interstitial fibrosis also developed in the course toward AF stabilization (Martins et al., 2014). Consistent with the above findings, other studies have demonstrated numerous transcriptional changes in ion channel expression (Deshmukh et al., 2015), including upregulation of KCNJ2 and KCNJ4 (encoding Kir2.1 and Kir2.3 subunits, respectively, which contribute to $\mathrm{I}_{\mathrm{K} 1}$ ) and downregulation of CACNA1C (encoding the $\mathrm{I}_{\mathrm{CaL}} \alpha$-subunit), CACNAB2 (a $\mathrm{I}_{\mathrm{CaL}} \beta$-subunit) (Deshmukh et al., 2015; Nattel, 2015), and CACNAC1D, which is atrial specific, and its absence in mice leads to impaired calcium homeostasis and increased AF susceptibility (Mancarella et al., 2008). Therefore, the progressive AF-related remodeling leading to DF increase in the animal model (Martins et al., 2014) is also consistent with the observation that the $\mathrm{AF}$ frequency is usually higher in patients with persistent than paroxysmal AF (Sanders et al., 2005). Sustained AF shortens APD and effective refractory period, decreasing the wavelength and facilitating the acceleration and stabilization of sustained reentry. The main determinants of APD shortening are the decrease in $I_{\mathrm{CaL}}$ and increase $I_{\mathrm{K} 1}$ (Dobrev et al., 2001; Martins et al., 2014).

\section{B. Remodeling and Upstream Therapies in Atrial Fibrillation}

Diverse pathologies such as hypertension, heart failure, or coronary heart disease, among others, can promote atrial remodeling, both electrically and structurally. In this context, "upstream" therapies aim to act 
on atrial remodeling and/or factors that promote it to control the burden of AF. More specifically, one of the most relevant objectives within upstream therapies is the control of atrial fibrosis, which is associated with the perpetuation of the arrhythmia.

Most of the scientific evidence focuses on inhibitors of the renin-angiotensin-aldosterone system (RAAS), such as angiotensin converting enzyme inhibitors (ACEIs) or angiotensin II receptor blockers (ARBs). The stimulation of angiotensin II receptors promotes nicotinamide adenine dinucleotide phosphate oxidase 2-dependent reactive oxygen species formation (Matsushima et al., 2014), producing oxidative stress and inflammation. In addition, angiotensin II activates an intracellular signaling cascade, leading to the activation of mitogen protein kinases to generate cardiomyocyte hypertrophy, apoptosis, and fibroblast proliferation, all favoring the perpetuation of $\mathrm{AF}$, potentiated by higher concentrations of angiotensin II in patients with $\mathrm{AF}$ (Bedecs et al., 1997; Novo et al., 2008).

In addition to the traditional ACEIs and ARBs, mineralocorticoid receptor blockers (MRBs) have also been shown to effectively reduce the incidence of newonset $\mathrm{AF}$ in systolic heart failure (HF) and to have beneficial effects on mortality in patients with cardiac disease (Lavall et al., 2014). From the mechanistic point of view, recent experimental results show clearly that the MRB eplerenone (EPL) significantly mitigates structural remodeling during the transition to persistent AF (Takemoto et al., 2017). Animals treated with EPL had significantly smaller atrial size and less cellular hypertrophy and fibrosis than animals given sugar pills. Atrial size is an important determinant of clinical AF (Takemoto et al., 2017). Experience in patients and numerical data suggest that dilated atria have a higher probability for initiation and maintenance of rotordriven fibrillatory activity (Pandit and Jalife, 2013). Myocyte hypertrophy was also diminished by EPL. The data are consistent with studies in mouse models of chronic pressure overload or myocardial infarction, in which deletion or inactivation of the MR gene attenuated left ventricular dilatation, cardiac hypertrophy, and development of HF, whereas MR overexpression in cardiomyocytes induced ventricular remodeling, development of $\mathrm{HF}$, and pro-arrhythmogenic effects (Ouvrard-Pascaud et al., 2005; Fraccarollo et al., 2011). Some RAAS pathways affected by ACEIs, ARBs, and MRBs are illustrated schematically in Fig. 3.

Several retrospective studies from clinical trials suggest a beneficial effect of the inhibition of RAAS in the prevention of $\mathrm{AF}$, especially in patients with ventricular hypertrophy or ventricular dysfunction. Among others, the EMPHASIS-HF study randomized 2743 patients with heart failure (ventricular ejection fraction $\leq 35 \%$ ) and functional class New York Heart Association $\geq$ II to receive EPL or placebo, the main objective of which was to analyze the incidence of new-onset $\mathrm{AF}$ during follow up. The investigators observed a significant reduction of new onset $\mathrm{AF}$ in the group randomized to EPL (2.7\% vs. 4.5\%) (Zannad et al., 2011). These data are supported by a recent meta-analysis that included 14 studies (five randomized clinical trials and nine observational studies) and 5332 patients, of whom 2397 received MRBs (EPL or spironolactone), which showed that the incidence of AF in this group was significantly lower compared with patients who did not receive this treatment $(8.5 \%$ and $18.6 \%$, respectively) (Neefs et al., 2017). Although the specific mechanism of action was not an objective of the work, the inhibition of fibrosis and atrial structural remodeling might be highly involved, as has been demonstrated in the animal model of persistent AF in sheep, with high similarity to clinical AF (Takemoto et al., 2016).

In line with the above findings, the RACE-3 study (Rienstra et al., 2018), whose results were presented at the congress of the European Society of Cardiology in August 2017, included patients with mild-to-moderate heart failure for less than 1 year and persistent $\mathrm{AF}$ with less than 5 years of history and episodes lasting less than 6 months, who were selected for electrical cardioversion. Patients were randomized to receive intensive treatment against cardiovascular risk factors and upstream therapy or perform conventional management. Upstream therapy included statins, ACEIs or ARBs, MRBs, and a cardiac rehabilitation program for 11 weeks. The main result of the study was that $75 \%$ of the patients within the intensive treatment group were in sinus rhythm during a year of follow up (including Holter registry of 7 days) compared with $63 \%$ in the group that received conventional management. Notably, there was no difference in antiarrhythmic drug use or the number of electrical cardioversions between the two groups. The results further increase the value of substrate control and comorbidities in the prevention of AF recurrences. It should be noted that the greatest differences between both groups were observed in therapy with MRBs (85\% vs. $4 \%$, in intensive vs. conventional therapy groups, respectively), which highlights their relevant role in the prevention of AF in patients with an obvious structural substrate.

Other studies such as GISSI-AF seemed to show conflicting data, since valsartan did not reduce the incidence of AF in secondary prevention. However, it is important to consider that half of the patients in both groups were under treatment with ACEIs (a fact that was not considered a possible confounding factor), and the patients had good ventricular function and, therefore, a low structural substrate and less influence of fibrosis-causing factors (Disertori et al., 2009).

A recent study demonstrated that intracardiac serum levels of the profibrotic protein galectin-3 (Gal-3) are greater in patients with persistent than paroxysmal $\mathrm{AF}$ and that Gal-3 is an independent predictor of atrial tachyarrhythmia recurrences after a single ablation procedure in some patients (Takemoto et al., 2016). In addition, upstream therapy targeting Gal-3 using a 


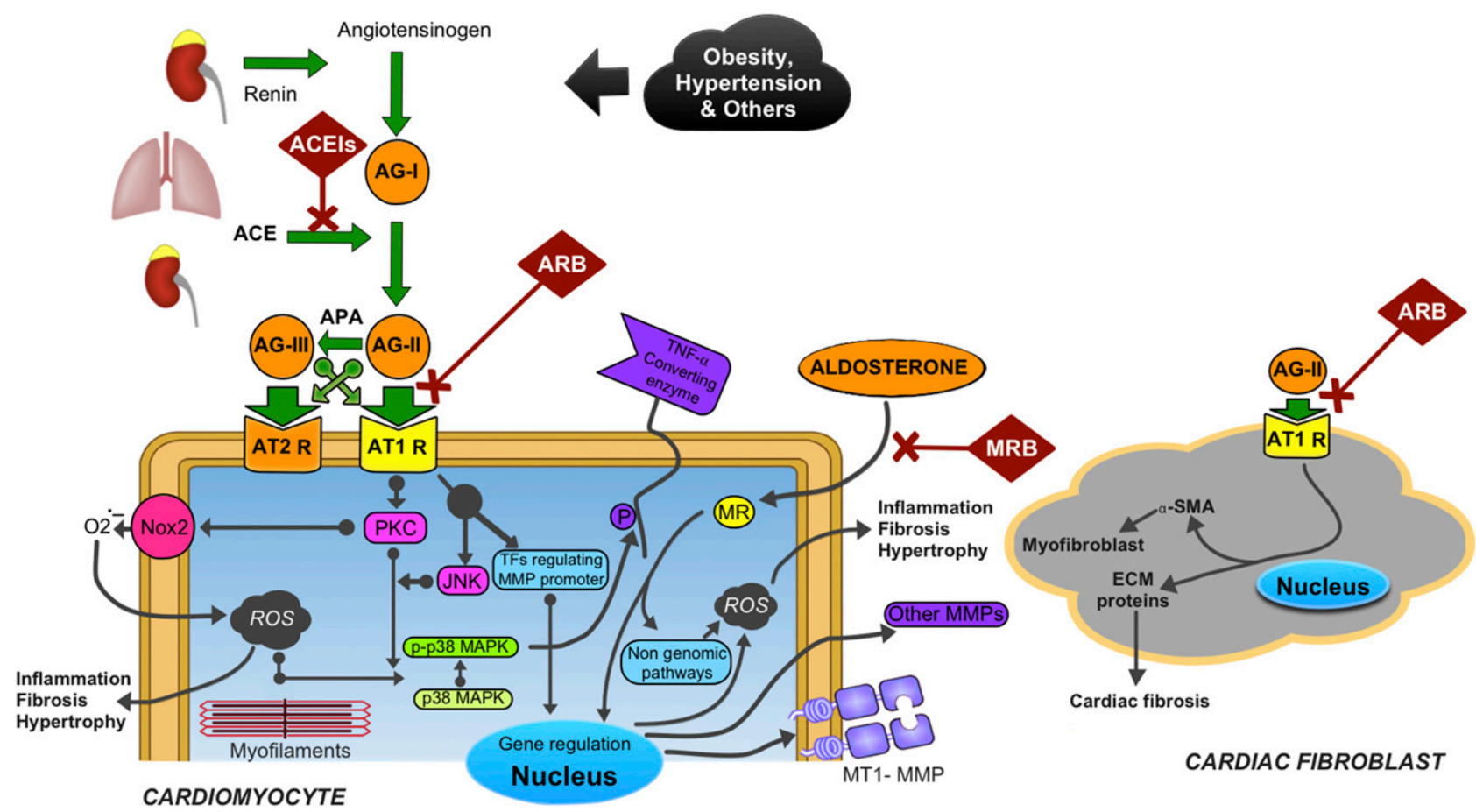

Fig. 3. Diagrammatic representation of the main effects exerted by renin-angiotensin-aldosterone system blockers. ACEIs, ARBs, and MRBs block inflammatory and profibrotic pathways that promote atrial remodeling and favor AF initiation and maintenance. ACEIs, angiotensin-converting enzyme inhibitors; AG-I, angiotensin I; AG-II, angiotensin II; AG-III, angiotensin III; APA, aminopeptidase A; ARB, angiotensin II type 1 receptor blocker; AT1R, angiotensin II type 1 receptor; AT2R, angiotensin II type 2 receptor; ECM, extracellular matrix; JNK, c-Jun N-terminal kinases; MMP, matrix metalloproteinase; MR, mineralocorticoid receptor; MRB, mineralocorticoid receptor blocker; MT1-MMP, membrane type 1 metalloprotease; Nox2, nicotinamide adenine dinucleotide phosphate oxidase 2; P, phosphorylation; p38 MAPK, p38 mitogen-activated protein kinase; PKC, protein kinase C; ROS, reactive oxygen species; SMA, $\alpha$-smooth muscle actin; TFs, transcription factors; TNF- $\alpha$, tumor necrosis factor- $\alpha$.

relatively low intravenous dose of the galactomannan GM-CT-01 reduced both structural and electrical remodeling as well as AF burden in a sheep model of persistent $\mathrm{AF}$ in the absence of comorbidities (Martins et al., 2014; Takemoto et al., 2016). However, Gal-3 inhibition did not restore sinus rhythm in the long term. Nevertheless, the study provided a solid proof of concept in support of upstream AF prevention therapy. Through its effects promoting gene transcription via cytokine-mediated signaling pathways (de Boer et al., 2009; Mackinnon et al., 2012), Gal-3 might represent but one of multiple potential targets for the prevention of either structural and/or electrical remodeling and AF perpetuation.

Less evidence exists in favor of therapies such as polyunsaturated omega-3 fatty acids or the inhibitors of 3-hydroxy-3-methylglutaryl-CoA reductase (statins) in isolation. To summarize, the dietary supplement with omega-3 polyunsaturated fatty acids could play a role in the prevention of $\mathrm{AF}$ in patients with evident structural substrate and presence of atrial remodeling, with high levels of circulating inflammatory biomarkers, and in the context of low circulating levels of the own polyunsaturated fatty acids omega-3 (Salvador-Montañés et al., 2012). In relation to statins, data from a metaanalysis suggest that statins may contribute to the prevention of $\mathrm{AF}$ in the postoperative period of cardiac surgery (Kuhn et al., 2014).
None of the agents described as "upstream" therapies to date have specific approval as an antiarrhythmic treatment against AF, but they are widely used drugs in cardiovascular disease and many of their current indications (e.g., hypertension) include most pathologies associated with $\mathrm{AF}$.

\section{Nonpharmacologic Targets: Obesity, Adiposis, and Inflammation in Atrial Fibrillation}

Upstream therapies not only involve pharmacological agents, but also other modifiable factors and measures such as the control of body weight, the treatment of obstructive sleep apnea, or the treatment and control of local or systemic inflammatory processes, which act on the structural or functional substrate that favors AF. Thus, obesity is a known risk factor for the development of AF; an increased body mass index, the presence of metabolic syndrome, and the diameter of the abdominal circumference have been identified as predictive factors for the development of AF (Zhang et al., 2009; Tanner et al., 2011). Current evidence from randomized clinical trials indicates that loss of weight gain is associated with a decrease in $\mathrm{AF}$ recurrences, as well as in the severity of the symptoms and the number of episodes (Abed et al., 2013). Therefore, the practice of moderate physical activity and avoiding excessive weight gain constitutes a preventive strategy for $\mathrm{AF}$, as well as 
recurrences after a first episode, as also evidenced by the CARDIO-FIT study (Pathak et al., 2015).

Cardiac adipose tissue consists of epicardial fat, overlying the epicardium, and the pericardial fat, situated outside the visceral pericardium and on the external surface of the parietal pericardium (Iacobellis, 2015). Under normal conditions, epicardial adipose tissue provides biochemical, mechanical, and thermogenic protective input to the myocardium (Iacobellis and Bianco, 2011). However, under pathologic conditions, epicardial fact can locally affect the myocardium, and recent studies suggest that, in addition to systemic adiposity, the volume of the pericardial fat of the entire heart, and particularly of that overlying the atria, may represent an even more important risk factor for AF. Many studies, including the Framingham Heart Study, have reported a relationship between the amount of adipose tissue that accumulates around the atria and the risk and maintenance of $\mathrm{AF}$ (Al Chekakie et al., 2010; Thanassoulis et al., 2010; Haemers et al., 2017). Also, epicardial fat is associated with AF severity and ablation outcomes (Wong et al., 2011). However, the underlying mechanisms linking $\mathrm{AF}$ to adipose tissue have not been elucidated.

In addition to being a rich source of free fatty acids (FFA), fat tissue can secret many proinflammatory cytokines (Iacobellis and Bianco, 2011; Iacobellis, 2015) that can freely diffuse into the adjacent myocardium (Mazurek et al., 2003; Iacobellis et al., 2005; Greulich et al., 2012) For instance, the secretome of human epicardial adipose tissue can induce atrial fibrosis, an effect that is mediated by Activin A (Venteclef et al., 2015). Epicardial adiposity and plasma levels of FFAs are elevated in AF (Rennison and Van Wagoner, 2009). FFAs have been shown to disrupt t-tubular architecture and to remodel properties of membrane ionic currents in sheep atrial myocytes, which might help explain their proarrhythmic effects (O'Connell et al., 2015). Crosstalk between adipose and myocardial tissue has been demonstrated by the observation that rapid atrial pacing or $\mathrm{AF}$ induces the expression of several genes able to regulate adipose tissue accumulation (Chilukoti et al., 2015). Adipose tissue can also infiltrate the myocardium and contribute to its functional disorganization as described for the right ventricle (Burke et al., 1998; Pouliopoulos et al., 2013). The inflammation of atrial tissue contributes to arrhythmogenic remodeling and could be a target of antiarrhythmic therapies. Corticosteroids have a potent anti-inflammatory effect and have been shown to be effective against $\mathrm{AF}$ in animal and clinical studies, but their potential adverse effects are a limitation for their use, especially in the long term.

\section{Atrial Fibrillation and Sleep Apnea}

Atrial arrhythmias, including AF, are highly prevalent in patients with moderate to severe obstructive sleep apnea, which is an independent risk factor for the development of AF. Some of the mechanisms involved include hypoxia, hypercapnia, increased atrial intracavitary pressure, inflammation itself, and negative intrathoracic pressure during the inspiratory effort of apnea. It is especially relevant that therapy with continuous positive airway pressure during sleep hours reduces or even eliminates the recurrence of atrial arrhythmias, not only AF (Filgueiras-Rama et al., 2013).

\section{Challenges and Opportunities in New Anti- atrial Fibrillation Drug Development}

The global AF market size was valued at USD 6.1 billion in 2012 and is expected to reach 8319 million by 2020 (https://www.alliedmarketresearch.com/atrialfibrillation-market). Fibrosis and electrical remodeling are now recognized to be major causes of AF perpetuation with consequent increase in morbidity and mortality (Dzeshka et al., 2015). The future growth of this market and the rising prevalence of $\mathrm{AF}$ in emerging Asian economies will ensure the success of future efforts for the discovery of novel biomarkers that could help advance preventative therapies that target specific mechanisms and signaling pathways involved in atrial remodeling and $\mathrm{AF}$ perpetuation and/or recurrence of the arrhythmia. Therefore, future research in AF mapping and ablation should be complemented by fundamental basic and translational science innovations in drug discovery, with the objective of preventing remodeling upstream, thus reducing AF burden, increasing the success of AF termination, and preventing recurrences. At the very least, such studies should dramatically improve our current understanding of the mechanisms underlying AF progression and perpetuation and help improve ablation outcomes.

There is a need to develop new and more effective therapies to cure or at least prevent the progression of AF to a chronic stage. The highly complex molecular underpinnings of atrial remodeling leading to persistent $\mathrm{AF}$ makes target identification challenging. Yet only a profound and complete understanding of the mechanisms involved in the maintenance and perpetuation of $\mathrm{AF}$ will allow us to generate more specific prevention and/or treatment of this dangerous and debilitating disease. Animal models play an important role in the study of the pathophysiology of AF, including molecular basis, ion-current determinants, anatomic features, and macroscopic mechanisms, as well as in the development of new therapeutic approaches, whether drug-based, molecular therapeutics, or device related (Nishida et al., 2010). Unfortunately, the scientific challenges to translational $\mathrm{AF}$ research taken together with the financial risks have led to significant reductions in the investment in treatments for new cardiovascular drugs both in the United States and globally (Fordyce et al., 2015). Many pharmaceutical companies have stopped almost entirely their antiarrhythmic drug 
research programs, focusing on therapeutic areas like oncology and Alzheimer's disease (DiMasi et al., 2010; Pammolli et al., 2011; Fordyce et al., 2015). However, reproducibility and collaboration among basic scientists, clinicians, and industry will be critical for translation into effective therapies.

\section{Conclusion}

The prevalence and burden of AF worldwide call for an urgent increase in investment in basic and translational research within industry, academia, and government. Significant advances in science and new approaches to translation are needed, so that vital scientific challenges are overcome, including increasing the understanding of $\mathrm{AF}$ mechanisms, identifying and validating targets, developing predictive biologic and computational models, recognizing reliable biomarkers for patient stratification and as endpoints for clinical trials, preventing proarrhythmia toward clearing regulatory pathways, and ensuring the reliability and reproducibility of published data, as well as data sharing and collaboration.

\section{Authorship Contributions}

Wrote or contributed to the writing of the manuscript: Calvo, Filgueiras Rama, Jalife.

\section{References}

Abed HS, Wittert GA, Leong DP, Shirazi MG, Bahrami B, Middeldorp ME, Lorimer MF, Lau DH, Antic NA, Brooks AG, et al. (2013) Effect of weight reduction and cardiometabolic risk factor management on symptom burden and severity in patients with atrial fibrillation: a randomized clinical trial. JAMA 310:2050-2060.

Abraham RL, Yang T, Blair M, Roden DM, and Darbar D (2010) Augmented potassium current is a shared phenotype for two genetic defects associated with familial atrial fibrillation. J Mol Cell Cardiol 48:181-190.

Aguilar M, Xiong F, Qi XY, Comtois P, and Nattel S (2015) Potassium channel blockade enhances atrial fibrillation-selective antiarrhythmic effects of optimized state-dependent sodium channel blockade. Circulation 132:2203-2211.

Al Chekakie MO, Welles CC, Metoyer R, Ibrahim A, Shapira AR, Cytron J, Santucci P, Wilber DJ, and Akar JG (2010) Pericardial fat is independently associated with human atrial fibrillation. J Am Coll Cardiol 56:784-788.

AlKadi HO (2007) Antimalarial drug toxicity: a review. Chemotherapy 53:385-391.

Allessie M, Ausma J, and Schotten U (2002) Electrical, contractile and structural remodeling during atrial fibrillation. Cardiovasc Res 54:230-246.

Allessie M and de Groot N (2014) CrossTalk opposing view: rotors have not been demonstrated to be the drivers of atrial fibrillation. J Physiol 592:3167-3170.

Alonso A, Krijthe BP, Aspelund T, Stepas KA, Pencina MJ, Moser CB, Sinner MF, Sotoodehnia N, Fontes JD, Janssens AC, et al. (2013) Simple risk model predicts incidence of atrial fibrillation in a racially and geographically diverse population: the CHARGE-AF consortium. $J$ Am Heart Assoc 2:e00102

Andrade J, Khairy P, Dobrev D, and Nattel S (2014) The clinical profile and pathophysiology of atrial fibrillation: relationships among clinical features, epidemiology, and mechanisms. Circ Res 114:1453-1468.

Arnar DO, Thorvaldsson S, Manolio TA, Thorgeirsson G, Kristjansson K, Hakonarson H, and Stefansson K (2006) Familial aggregation of atrial fibrillation in Iceland. Eur Heart $J$ 27:708-712.

Arora R, Ulphani JS, Villuendas R, Ng J, Harvey L, Thordson S, Inderyas F, Lu Y, Gordon D, Denes P, et al. (2008) Neural substrate for atrial fibrillation: implications for targeted parasympathetic blockade in the posterior left atrium. Am J Physiol Heart Circ Physiol 294:H134-H144.

Arora R, Verheule S, Scott L, Navarrete A, Katari V, Wilson E, Vaz D, and Olgin JE (2003) Arrhythmogenic substrate of the pulmonary veins assessed by highresolution optical mapping. Circulation 107:1816-1821.

Arya A, Silberbauer J, Teichman SL, Milner P, Sulke N, and Camm AJ (2009) A preliminary assessment of the effects of ATI-2042 in subjects with paroxysmal atrial fibrillation using implanted pacemaker methodology. Europace 11:458-464.

Atienza F, Almendral J, Moreno J, Vaidyanathan R, Talkachou A, Kalifa J, Arenal A, Villacastín JP, Torrecilla EG, Sánchez A, et al. (2006) Activation of inward rectifier potassium channels accelerates atrial fibrillation in humans: evidence for a reentrant mechanism. Circulation 114:2434-2442.

Atienza F, Almendral J, Ormaetxe JM, Moya A, Martínez-Alday JD, HernándezMadrid A, Castellanos E, Arribas F, Arias MA, Tercedor L, et al.; RADAR-AF Investigators (2014) Comparison of radiofrequency catheter ablation of drivers and circumferential pulmonary vein isolation in atrial fibrillation: a noninferiority randomized multicenter RADAR-AF trial. J Am Coll Cardiol 64:2455-2467.
Banerjee A, Taillandier S, Olesen JB, Lane DA, Lallemand B, Lip GY, and Fauchier L (2013) Pattern of atrial fibrillation and risk of outcomes: the Loire valley atrial fibrillation project. Int $J$ Cardiol 167:2682-2687.

Bapat A, Anderson CD, Ellinor PT, and Lubitz SA (2018) Genomic basis of atrial fibrillation. Heart 104:201-206

Barrabés JA, Figueras J, Candell-Riera J, Agulló L, Inserte J, and Garcia-Dorado D (2013) Distension of the ischemic region predicts increased ventricular fibrillation inducibility following coronary occlusion in swine. Rev Esp Cardiol (Engl Ed) 66:171-176.

Bedecs K, Elbaz N, Sutren M, Masson M, Susini C, Strosberg AD, and Nahmias C (1997) Angiotensin II type 2 receptors mediate inhibition of mitogen-activated protein kinase cascade and functional activation of SHP-1 tyrosine phosphatase. Biochem J 325:449-454.

Benjamin EJ, Levy D, Vaziri SM, D’Agostino RB, Belanger AJ, and Wolf PA (1994) Independent risk factors for atrial fibrillation in a population-based cohort. The Framingham heart study. JAMA 271:840-844.

Bikou O, Thomas D, Trappe K, Lugenbiel P, Kelemen K, Koch M, Soucek R, Voss F, Becker R, Katus HA, et al. (2011) Connexin 43 gene therapy prevents persistent atrial fibrillation in a porcine model. Cardiovasc Res 92:218-225.

Blaauw Y, Gögelein H, Tieleman RG, van Hunnik A, Schotten U, and Allessie MA (2004) "Early" class III drugs for the treatment of atrial fibrillation: efficacy and atrial selectivity of AVE0118 in remodeled atria of the goat. Circulation 110: $1717-1724$

Black-Maier EW, Pokorney SD, Barnett AS, Liu P, Shrader P, Ng J, Goldberger JJ, Zareba W, Daubert JP, Grant AO, et al. (2017) Ranolazine reduces atrial fibrillatory wave frequency. Europace 19:1096-1100.

Bode F, Katchman A, Woosley RL, and Franz MR (2000) Gadolinium decreases stretch-induced vulnerability to atrial fibrillation. Circulation 101:2200-2205.

Bode F, Sachs F, and Franz MR (2001) Tarantula peptide inhibits atrial fibrillation. Nature 409:35-36.

Burashnikov A, Belardinelli L, and Antzelevitch C (2010) Acute dronedarone is inferior to amiodarone in terminating and preventing atrial fibrillation in canine atria. Heart Rhythm 7:1273-1279.

Burashnikov A, Di Diego JM, Zygmunt AC, Belardinelli L, and Antzelevitch C (2007) Atrium-selective sodium channel block as a strategy for suppression of atrial fibrillation: differences in sodium channel inactivation between atria and ventricles and the role of ranolazine. Circulation 116:1449-1457.

Burashnikov A, Petroski A, Hu D, Barajas-Martinez H, and Antzelevitch C (2012) Atrial-selective inhibition of sodium-channel current by Wenxin Keli is effective in suppressing atrial fibrillation. Heart Rhythm 9:125-131.

Burke AP, Farb A, Tashko G, and Virmani R (1998) Arrhythmogenic right ventricular cardiomyopathy and fatty replacement of the right ventricular myocardium: are they different diseases? Circulation 97:1571-1580.

Burrell ZL Jr and Martinez AC (1958) Chloroquine and hydroxychloroquine in the treatment of cardiac arrhythmias. N Engl J Med 258:798-800.

Caballero R, de la Fuente MG, Gómez R, Barana A, Amorós I, Dolz-Gaitón P, Osuna L, Almendral J, Atienza F, Fernández-Avilés F, et al. (2010) In humans, chronic atrial fibrillation decreases the transient outward current and ultrarapid component of the delayed rectifier current differentially on each atria and increases the slow component of the delayed rectifier current in both. J Am Coll Cardiol 55: $2346-2354$

Calkins H, Brugada J, Packer DL, Cappato R, Chen SA, Crijns HJ, Damiano RJ Jr, Davies DW, Haines DE, Haissaguerre M et al. European Heart Rhythm Association (EHRA); European Cardiac Arrhythmia Scoiety (ECAS); American College of Cardiology (ACC); American Heart Association (AHA); Society of Thoracic Surgeons (STS) (2007) HRS/EHRA/ECAS expert consensus statement on catheter and surgical ablation of atrial fibrillation: recommendations for personnel, policy, procedures and follow-up. A report of the Heart Rhythm Society (HRS) task force on catheter and surgical ablation of atrial fibrillation. Heart Rhythm 4:816-861.

Calkins H, Hindricks G, Cappato R, Kim YH, Saad EB, Aguinaga L, Akar JG, Badhwar V, Brugada J, Camm J, et al. (2017) 2017 HRS/EHRA/ECAS/APHRS/SOLAECE expert consensus statement on catheter and surgical ablation of atrial fibrillation. Heart Rhythm 14:e275-e444.

Calvo CJ, Deo M, Zlochiver S, Millet J, and Berenfeld O (2014) Attraction of rotors to the pulmonary veins in paroxysmal atrial fibrillation: a modeling study. Biophys $J$ 106:1811-1821.

Calvo D and Jalife $J$ (2013) Mechanoelectric feedback in the ischemic myocardium: an interplay that modulates susceptibility to fibrillation. Rev Esp Cardiol (Engl Ed) 66:168-170.

Calvo D, Rubín J, Pérez D, and Morís C (2017) Ablation of rotor domains effectively modulates dynamics of human: long-standing persistent atrial fibrillation. Circ Arrhythm Electrophysiol 10: e005740.

Camm AJ, Camm CF, and Savelieva I (2012) Medical treatment of atrial fibrillation. $J$ Cardiovasc Med (Hagerstown) 13:97-107.

Camm AJ, Capucci A, Hohnloser SH, Torp-Pedersen C, Van Gelder IC, Mangal B, and Beatch G; AVRO Investigators (2011) A randomized active-controlled study comparing the efficacy and safety of vernakalant to amiodarone in recent-onset atrial fibrillation. J Am Coll Cardiol 57:313-321.

Camm AJ, Kirchhof P, Lip GY, Schotten U, Savelieva I, Ernst S, Van Gelder IC, AlAttar N, Hindricks G, Prendergast B, et al.; ESC Committee for Practice Guidelines (2010) Guidelines for the management of atrial fibrillation: the task force for the management of atrial fibrillation of the European Society of Cardiology (ESC) [published correction appears in Europace (2011) 13:1058]. Europace 12: 1360-1420.

Cappato R, Calkins H, Chen SA, Davies W, Iesaka Y, Kalman J, Kim YH, Klein G, Packer D, and Skanes A (2005) Worldwide survey on the methods, efficacy, and safety of catheter ablation for human atrial fibrillation. Circulation 111: $1100-1105$

Cea-Calvo L, Redón J, Lozano JV, Fernández-Pérez C, Martí-Canales JC, Llisterri JL, González-Esteban J, and Aznar J; Investigators of the PREV-ICTUS Study (2007) Prevalence of atrial fibrillation in the Spanish population aged 60 years or more. The PREV-ICTUS study. Rev Esp Cardiol 60:616-624. 
Cha TJ, Ehrlich JR, Chartier D, Qi XY, Xiao L, and Nattel S (2006) Kir3-based inward rectifier potassium current: potential role in atrial tachycardia remodeling effects on atrial repolarization and arrhythmias. Circulation 113:1730-1737.

Chang KC, Bayer JD, and Trayanova NA (2014) Disrupted calcium release as a mechanism for atrial alternans associated with human atrial fibrillation. PLOS Comput Biol 10:e1004011.

Chang KC and Trayanova NA (2016) Mechanisms of arrhythmogenesis related to calcium-driven alternans in a model of human atrial fibrillation. Sci Rep 6:36395. Chang SL, Chen YC, Chen YJ, Wangcharoen W, Lee SH, Lin CI, and Chen SA (2007) Mechanoelectrical feedback regulates the arrhythmogenic activity of pulmonary veins. Heart 93:82-88.

Chen Y, Nie S, Gao H, Sun T, Liu X, Teng F, Xing Y, Chen W, Zhang Z, Gao Y, et al (2013) The effects of wenxin keli on p-wave dispersion and maintenance of sinus rhythm in patients with paroxysmal atrial fibrillation: a meta-analysis of randomized controlled trials. Evid Based Complement Alternat Med 2013:245958.

Chen YH, Xu SJ, Bendahhou S, Wang XL, Wang Y, Xu WY, Jin HW, Sun H, Su XY, Zhuang QN, et al. (2003) KCNQ1 gain-of-function mutation in familial atrial fibrillation. Science 299:251-254.

Chiang CE, Naditch-Brûlé L, Murin J, Goethals M, Inoue H, O'Neill J, Silva-Cardoso $\mathrm{J}$, Zharinov O, Gamra H, Alam S, et al. (2012) Distribution and risk profile of paroxysmal, persistent, and permanent atrial fibrillation in routine clinical practice: insight from the real-life global survey evaluating patients with atrial fibrillation international registry. Circ Arrhythm Electrophysiol 5:632-639.

Chilukoti RK, Giese A, Malenke W, Homuth G, Bukowska A, Goette A, Felix SB Kanaan J, Wollert HG, Evert K, et al. (2015) Atrial fibrillation and rapid acute pacing regulate adipocyte/adipositas-related gene expression in the atria. Int $J$ Cardiol 187:604-613.

Chinchilla A, Daimi H, Lozano-Velasco E, Dominguez JN, Caballero R, Delpón E, Tamargo J, Cinca J, Hove-Madsen L, Aranega AE, et al. (2011) PITX2 insufficiency leads to atrial electrical and structural remodeling linked to arrhythmogenesis. Circ Cardiovasc Genet 4:269-279.

Christophersen IE, Rienstra M, Roselli C, Yin X, Geelhoed B, Barnard J, Lin H, Arking DE, Smith AV, Albert CM, et al.; METASTROKE Consortium of the ISGC; Neurology Working Group of the CHARGE Consortium; AFGen Consortium (2017) Large-scale analyses of common and rare variants identify 12 new loci associated with atrial fibrillation [published correction appears in Nat Genet (2017) 49:1286]. Nat Genet 49:946-952.

Chugh SS, Havmoeller R, Narayanan K, Singh D, Rienstra M, Benjamin EJ, Gillum RF, Kim YH, McAnulty JH Jr, Zheng ZJ, et al. (2014) Worldwide epidemiology of atrial fibrillation: a global burden of disease 2010 study. Circulation 129:837-847.

Colilla S, Crow A, Petkun W, Singer DE, Simon T, and Liu X (2013) Estimates of current and future incidence and prevalence of atrial fibrillation in the U.S. adult population. Am J Cardiol 112:1142-1147.

Cox JL, Boineau JP, Schuessler RB, Ferguson TB Jr, Cain ME, Lindsay BD, Corr PB Kater KM, and Lappas DG (1991) Successful surgical treatment of atrial fibrillation. Review and clinical update. JAMA 266:1976-1980.

Cranefield PF and Aronson RS (1988) Cardiac Arrhythmias: The Role of Triggered Activity, Futura Publishing Co. Inc., Mount Kisko, NY.

Darbar D, Motsinger AA, Ritchie MD, Gainer JV, and Roden DM (2007) Polymorphism modulates symptomatic response to antiarrhythmic drug therapy in patients with lone atrial fibrillation. Heart Rhythm 4:743-749.

Das S, Makino S, Melman YF, Shea MA, Goyal SB, Rosenzweig A, Macrae CA and Ellinor PT (2009) Mutation in the S3 segment of KCNQ1 results in familial lone atrial fibrillation. Heart Rhythm 6:1146-1153.

de Boer RA, Voors AA, Muntendam P, van Gilst WH, and van Veldhuisen DJ (2009) Galectin-3: a novel mediator of heart failure development and progression. Eur $J$ Heart Fail 11:811-817.

De Ferrari GM, Maier LS, Mont L, Schwartz PJ, Simonis G, Leschke M, Gronda E, Boriani G, Darius H, Guillamón Torán L, et al.; RAFFAELLO Investigators (see Online Supplementary Appendix for List of Participating Centers and Investigators) (2015) Ranolazine in the treatment of atrial fibrillation: results of the doseranging RAFFAELLO (Ranolazine in Atrial Fibrillation Following An ELectricaL CardiOversion) study. Heart Rhythm 12:872-878.

de Groot N, van der Does L, Yaksh A, Lanters E, Teuwen C, Knops P, van de Woestijne P, Bekkers J, Kik C, Bogers A, et al. (2016) Direct proof of endoepicardial asynchrony of the atrial wall during atrial fibrillation in humans. Circ Arrhythm Electrophysiol 9:e003648.

de Groot NM, Houben RP, Smeets JL, Boersma E, Schotten U, Schalij MJ, Crijns H, and Allessie MA (2010) Electropathological substrate of longstanding persisten atrial fibrillation in patients with structural heart disease: epicardial breakthrough. Circulation 122:1674-1682.

Deshmukh A, Barnard J, Sun H, Newton D, Castel L, Pettersson G, Johnston D, Roselli E, Gillinov AM, McCurry K, et al. (2015) Left atrial transcriptional changes associated with atrial fibrillation susceptibility and persistence. Circ Arrhythm Electrophysiol 8:32-41.

de Vos CB, Pisters R, Nieuwlaat R, Prins MH, Tieleman RG, Coelen RJ, van den Heijkant AC, Allessie MA, and Crijns HJ (2010) Progression from paroxysmal to persistent atrial fibrillation clinical correlates and prognosis. J Am Coll Cardiol $\mathbf{5 5}$ 725-731.

DiMasi JA, Feldman L, Seckler A, and Wilson A (2010) Trends in risks associated with new drug development: success rates for investigational drugs. Clin Pharmacol Ther 87:272-277.

Diness JG, Skibsbye L, Simó-Vicens R, Santos JL, Lundegaard P, Citerni C, Sauter DRP, Bomholtz SH, Svendsen JH, Olesen SP, et al (2017) Termination of vernakalantresistant atrial fibrillation by inhibition of small-conductance $\mathrm{Ca}^{2+}$-activated $\mathrm{K}^{+}$channels in pigs. Circ Arrhythm Electrophysiol 10:e005125.

Diness JG, Sørensen US, Nissen JD, Al-Shahib B, Jespersen T, Grunnet M, and Hansen RS (2010) Inhibition of small-conductance Ca2+-activated K+ channels terminates and protects against atrial fibrillation. Circ Arrhythm Electrophysiol 3:380-390.

Di Pasquale G, Mathieu G, Maggioni AP, Fabbri G, Lucci D, Vescovo G, Pirelli S, Chiarella F, Scherillo M, Gulizia MM, et al.; ATA-AF Investigators (2013) Current presentation and management of 7148 patients with atrial fibrillation in cardiology and internal medicine hospital centers: the ATA AF study. Int $J$ Cardiol 167: 2895-2903.

Disertori M, Latini R, Barlera S, Franzosi MG, Staszewsky L, Maggioni AP, Lucci D, Di Pasquale G, and Tognoni G; GISSI-AF Investigators (2009) Valsartan for prevention of recurrent atrial fibrillation [published correction appears in $N \mathrm{Engl} J$ Med (2009) 360:2379]. N Engl J Med 360:1606-1617.

Dobrev D, Friedrich A, Voigt N, Jost N, Wettwer E, Christ T, Knaut M, and Ravens U (2005) The G protein-gated potassium current $\mathrm{I}(\mathrm{K}, \mathrm{ACh})$ is constitutively active in patients with chronic atrial fibrillation. Circulation 112:3697-3706.

Dobrev D, Graf E, Wettwer E, Himmel HM, Hála O, Doerfel C, Christ T, Schüler S, and Ravens U (2001) Molecular basis of downregulation of G-protein-coupled inward rectifying $\mathrm{K}(+)$ current $(\mathrm{I}(\mathrm{K}, \mathrm{ACh})$ in chronic human atrial fibrillation: decrease in GIRK4 mRNA correlates with reduced $\mathrm{I}(\mathrm{K}, \mathrm{ACh})$ and muscarinic receptormediated shortening of action potentials. Circulation 104:2551-2557.

Doggrell SA and Hancox JC (2004) Dronedarone: an amiodarone analogue. Expert Opin Investig Drugs 13:415-426.

Dorian P, Pinter A, Mangat I, Korley V, Cvitkovic SS, and Beatch GN (2007) The effect of vernakalant (RSD1235), an investigational antiarrhythmic agent, on atrial electrophysiology in humans. J Cardiovasc Pharmacol 50:35-40.

Du X, Zhang H, Lopes C, Mirshahi T, Rohacs T, and Logothetis DE (2004) Characteristic interactions with phosphatidylinositol 4,5-bisphosphate determine regulation of kir channels by diverse modulators. J Biol Chem 279:37271-37281.

Dzeshka MS, Lip GY, Snezhitskiy V, and Shantsila E (2015) Cardiac fibrosis in patients with atrial fibrillation: mechanisms and clinical implications. $J$ Am Coll Cardiol 66:943-959.

Echt DS, Liebson PR, Mitchell LB, Peters RW, Obias-Manno D, Barker AH, Arensberg D, Baker A, Friedman L, Greene HL, et al. (1991) Mortality and morbidity in patients receiving encainide, flecainide, or placebo. The cardiac arrhythmia suppression trial. $N$ Engl J Med 324:781-788.

Ehrlich JR, Cha TJ, Zhang L, Chartier D, Melnyk P, Hohnloser SH, and Nattel S (2003) Cellular electrophysiology of canine pulmonary vein cardiomyocytes: action potential and ionic current properties. J Physiol 551:801-813.

Ehrlich JR, Ocholla H, Ziemek D, Rütten H, Hohnloser SH, and Gögelein H (2008) Characterization of human cardiac Kv1.5 inhibition by the novel atrial-selective antiarrhythmic compound AVE1231. J Cardiovasc Pharmacol 51:380-387.

Enriquez A, Liang JJ, Santangeli P, Marchlinski FE, and Riley MP (2017) Focal atrial fibrillation from the superior vena cava. J Atr Fibrillation 9:1593.

Ezekowitz MD, Nagarakanti R, Lubinski A, Bandman O, Canafax D, Ellis DJ, Milner PG, Ziola M, Thibault B, and Hohnloser SH; PASCAL Investigators (2012) A randomized trial of budiodarone in paroxysmal atrial fibrillation. $J$ Interv Card Electrophysiol 34:1-9.

Filgueiras-Rama D, Arias MA, Iniesta A, Armada E, Merino JL, Peinado R, and López-Sendón JL (2013) Atrial arrhythmias in obstructive sleep apnea: underlying mechanisms and implications in the clinical setting. Pulm Med 2013: 426758.

Filgueiras-Rama D, Martins RP, Mironov S, Yamazaki M, Calvo CJ, Ennis SR, Bandaru K, Noujaim SF, Kalifa J, Berenfeld O, et al. (2012) Chloroquine terminates stretch-induced atrial fibrillation more effectively than flecainide in the sheep heart. Circ Arrhythm Electrophysiol 5:561-570.

Fitzmaurice DA, Hobbs FD, Jowett S, Mant J, Murray ET, Holder R, Raftery JP Bryan S, Davies M, Lip GY, et al. (2007) Screening versus routine practice in detection of atrial fibrillation in patients aged 65 or over: cluster randomised controlled trial. BMJ 335:383.

Flaherty DP, Simpson DS, Miller M, Maki BE, Zou B, Shi J, Wu M, McManus OB, Aubé J, Li M, et al. (2014) Potent and selective inhibitors of the TASK-1 potassium channel through chemical optimization of a bis-amide scaffold. Bioorg Med Chem Lett 24:3968-3973.

Fordyce CB, Roe MT, Ahmad T, Libby P, Borer JS, Hiatt WR, Bristow MR, Packer M, Wasserman SM, Braunstein N, et al. (2015) Cardiovascular drug development: is it dead or just hibernating? J Am Coll Cardiol 65:1567-1582.

Fox CS, Parise H, D'Agostino RB Sr, Lloyd-Jones DM, Vasan RS, Wang TJ, Levy D, Wolf PA, and Benjamin EJ (2004) Parental atrial fibrillation as a risk factor for atrial fibrillation in offspring. JAMA 291:2851-2855.

Fozzard HA (1992) Afterdepolarizations and triggered activity. Basic Res Cardiol 87 (Suppl 2):105-113.

Fraccarollo D, Berger S, Galuppo P, Kneitz S, Hein L, Schütz G, Frantz S, Ertl G, and Bauersachs J (2011) Deletion of cardiomyocyte mineralocorticoid receptor ameliorates adverse remodeling after myocardial infarction. Circulation 123 400-408.

Franz MR and Bode F (2003) Mechano-electrical feedback underlying arrhythmias: the atrial fibrillation case. Prog Biophys Mol Biol 82:163-174.

Furukawa T, Koumi S, Sakakibara Y, Singer DH, Jia H, Arentzen CE, Backer CL, and Wasserstrom JA (1995) An analysis of lidocaine block of sodium current in isolated human atrial and ventricular myocytes. J Mol Cell Cardiol 27:831-846.

Gautier P, Guillemare E, Djandjighian L, Marion A, Planchenault J, Bernhart C, Herbert JM, and Nisato D (2004) In vivo and in vitro characterization of the novel antiarrhythmic agent SSR149744C: electrophysiological, anti-adrenergic, and antiangiotensin II effects. $J$ Cardiovasc Pharmacol 44:244-257.

Gautier P, Serre M, Cosnier-Pucheu S, Djandjighian L, Roccon A, Herbert JM, and Nisato D (2005) In vivo and in vitro antiarrhythmic effects of SSR149744C in animal models of atrial fibrillation and ventricular arrhythmias. J Cardiovasc Pharmacol 45:125-135.

Gherghiceanu M, Hinescu ME, Andrei F, Mandache E, Macarie CE, FaussonePellegrini MS, and Popescu LM (2008) Interstitial Cajal-like cells (ICLC) in myocardial sleeves of human pulmonary veins. J Cell Mol Med 12:1777-17781.

Gierten J, Ficker E, Bloehs R, Schweizer PA, Zitron E, Scholz E, Karle C, Katus HA and Thomas D (2010) The human cardiac K2P3.1 (TASK-1) potassium leak channel is a molecular target for the class III antiarrhythmic drug amiodarone. Naunyn Schmiedebergs Arch Pharmacol 381:261-270.

Girmatsion Z, Biliczki P, Bonauer A, Wimmer-Greinecker G, Scherer M, Moritz A, Bukowska A, Goette A, Nattel S, Hohnloser SH, et al. (2009) Changes in 
microRNA-1 expression and IK1 up-regulation in human atrial fibrillation. Heart Rhythm 6:1802-1809.

Greulich S, Maxhera B, Vandenplas G, de Wiza DH, Smiris K, Mueller H, Heinrichs J, Blumensatt M, Cuvelier C, Akhyari P, et al. (2012) Secretory products from epicardial adipose tissue of patients with type 2 diabetes mellitus induce cardiomyocyte dysfunction. Circulation 126:2324-2334.

Gros D, Jarry-Guichard T, Ten Velde I, de Maziere A, van Kempen MJ, Davoust J, Briand JP, Moorman AF, and Jongsma HJ (1994) Restricted distribution of connexin40, a gap junctional protein, in mammalian heart. Circ Res $\mathbf{7 4}$ $839-851$.

Gudbjartsson DF, Arnar DO, Helgadottir A, Gretarsdottir S, Holm H, Sigurdsson A Jonasdottir A, Baker A, Thorleifsson G, Kristjansson K, et al. (2007) Variants conferring risk of atrial fibrillation on chromosome 4q25. Nature 448:353-357.

Guillemare E, Marion A, Nisato D, and Gautier P (2000) Inhibitory effects of dronedarone on muscarinic $\mathrm{K}+$ current in guinea pig atrial cells. $J$ Cardiovasc Pharmacol 36:802-805.

Haemers P, Hamdi H, Guedj K, Suffee N, Farahmand P, Popovic N, Claus P, LePrince P, Nicoletti A, Jalife J, et al. (2017) Atrial fibrillation is associated with the fibrotic remodelling of adipose tissue in the subepicardium of human and sheep atria. Eur Heart $J$ 38:53-61.

Haïssaguerre M, Jaïs P, Shah DC, Takahashi A, Hocini M, Quiniou G, Garrigue S, Le Mouroux A, Le Métayer P, and Clémenty J (1998) Spontaneous initiation of atrial fibrillation by ectopic beats originating in the pulmonary veins. N Engl J Med 339 $659-666$.

Halsey C and Chugh A (2014) Rate versus rhythm control for atrial fibrillation. Cardiol Clin 32:521-531.

Hancock JM, Weatherall KL, Choisy SC, James AF, Hancox JC, and Marrion NV (2015) Selective activation of heteromeric SK channels contributes to action potential repolarization in mouse atrial myocytes. Heart Rhythm 12:1003-1015.

Hancox JC, James AF, Marrion NV, Zhang H, and Thomas D (2016) Novel ion channel targets in atrial fibrillation. Expert Opin Ther Targets 20:947-958.

Hanley CM, Robinson VM, and Kowey PR (2016) Status of antiarrhythmic drug development for atrial fibrillation: new drugs and new molecular mechanisms. Circ Arrhythm Electrophysiol 9:e002479.

Hart RG (2003) Atrial fibrillation and stroke prevention. N Engl J Med 349: 1015-1016.

Hartmann N, Pabel S, Herting J, Schatter F, Renner A, Gummert J, Schotola H, Danner BC, Maier LS, Frey N, et al. (2017) Antiarrhythmic effects of dantrolene in human diseased cardiomyocytes. Heart Rhythm 14:412-419.

Haugan K, Miyamoto T, Takeishi Y, Kubota I, Nakayama J, Shimojo H, and Hirose M (2006) Rotigaptide (ZP123) improves atrial conduction slowing in chronic volume overload-induced dilated atria. Basic Clin Pharmacol Toxicol 99:71-79.

Heijman J, Voigt N, Nattel S, and Dobrev D (2014) Cellular and molecular electrophysiology of atrial fibrillation initiation, maintenance, and progression. Circ Res 114:1483-1499.

Hocini M, Ho SY, Kawara T, Linnenbank AC, Potse M, Shah D, Jaïs P, Janse MJ Haïssaguerre M, and De Bakker JM (2002) Electrical conduction in canine pulmonary veins: electrophysiological and anatomic correlation. Circulation 105 $2442-2448$.

Holt DW, Tucker GT, Jackson PR, and Storey GC (1983) Amiodarone pharmacokinetics. Am Heart $J$ 106:840-847.

Hsueh CH, Chang PC, Hsieh YC, Reher T, Chen PS, and Lin SF (2013) Proarrhythmic effect of blocking the small conductance calcium activated potassium channel in isolated canine left atrium. Heart Rhythm 10:891-898.

Hu D, Barajas-Martínez H, Burashnikov A, Panama BK, Cordeiro JM, and Antzelevitch C (2016) Mechanisms underlying atrial-selective block of sodium channels by Wenxin Keli: experimental and theoretical analysis. Int $J$ Cardiol 207:326-334.

Iacobellis G (2015) Local and systemic effects of the multifaceted epicardial adipose tissue depot. Nat Rev Endocrinol 11:363-371.

Iacobellis G and Bianco AC (2011) Epicardial adipose tissue: emerging physiological, pathophysiological and clinical features. Trends Endocrinol Metab 22:450-457.

Iacobellis G, Corradi D, and Sharma AM (2005) Epicardial adipose tissue: anatomic, biomolecular and clinical relationships with the heart. Nat Clin Pract Cardiovasc Med 2:536-543.

Igarashi T, Finet JE, Takeuchi A, Fujino Y, Strom M, Greener ID, Rosenbaum DS, and Donahue JK (2012) Connexin gene transfer preserves conduction velocity and prevents atrial fibrillation. Circulation 125:216-225.

Jahangir A, Lee V, Friedman PA, Trusty JM, Hodge DO, Kopecky SL, Packer DL, Hammill SC, Shen WK, and Gersh BJ (2007) Long-term progression and outcomes with aging in patients with lone atrial fibrillation: a 30-year follow-up study. Circulation 115:3050-3056.

Jalife J (2011) Déjà vu in the theories of atrial fibrillation dynamics. Cardiovasc Res 89:766-775.

Jalife J, Berenfeld O, and Mansour M (2002) Mother rotors and fibrillatory conduction: a mechanism of atrial fibrillation. Cardiovasc Res 54:204-216.

Jalife J and Kaur K (2015) Atrial remodeling, fibrosis, and atrial fibrillation. Trends Cardiovasc Med 25:475-484.

Judge DP (2012) The complex genetics of atrial fibrillation. J Am Coll Cardiol 60 $1182-1184$

Juhász A and Bodor N (2000) Cardiovascular studies on different classes of soft drugs. Pharmazie 55:228-238.

Jung CB, Moretti A, Mederos y Schnitzler M, Iop L, Storch U, Bellin M, Dorn T, Ruppenthal S, Pfeiffer S, Goedel A, et al. (2012) Dantrolene rescues arrhythmogenic RYR2 defect in a patient-specific stem cell model of catecholaminergic polymorphic ventricular tachycardia. EMBO Mol Med 4:180-191.

Kalifa J, Tanaka K, Zaitsev AV, Warren M, Vaidyanathan R, Auerbach D, Pandit S, Vikstrom KL, Ploutz-Snyder R, Talkachou A, et al. (2006) Mechanisms of wave fractionation at boundaries of high-frequency excitation in the posterior left atrium of the isolated sheep heart during atrial fibrillation. Circulation 113:626-633.

Kanagaratnam L, Kowey P, and Whalley D (2017) Pharmacological therapy for rate and rhythm control for atrial fibrillation in 2017. Heart Lung Circ 26:926-933.
Khitri AR, Aliot EM, Capucci A, Connolly SJ, Crijns H, Hohnloser SH, Kulakowski P, Roy D, Radzik D, and Kowey PR (2012) Celivarone for maintenance of sinus rhythm and conversion of atrial fibrillation/flutter. J Cardiovasc Electrophysiol $\mathbf{2 3}$ : $462-472$.

Kirchhof P, Ammentorp B, Darius H, De Caterina R, Le Heuzey JY, Schilling RJ, Schmitt J, and Zamorano JL (2014) Management of atrial fibrillation in seven European countries after the publication of the 2010 ESC guidelines on atrial fibrillation: primary results of the PREvention oF thromboemolic events-European Registry in Atrial Fibrillation (PREFER in AF). Europace 16:6-14.

Kirchhof P, Benussi S, Kotecha D, Ahlsson A, Atar D, Casadei B, Castella M, Diener HC, Heidbuchel H, Hendriks J, et al.; ESC Scientific Document Group (2016) 2016 ESC guidelines for the management of atrial fibrillation developed in collaboration with EACTS. Eur Heart $J$ 37:2893-2962.

Kirchhof P, Kahr PC, Kaese S, Piccini I, Vokshi I, Scheld HH, Rotering H, For tmueller L, Laakmann S, Verheule S, et al. (2011) PITX2c is expressed in the adult left atrium, and reducing Pitx2c expression promotes atrial fibrillation inducibility and complex changes in gene expression. Circ Cardiovasc Genet 4:123-133.

Klos M, Calvo D, Yamazaki M, Zlochiver S, Mironov S, Cabrera JA, Sanchez-Quintana D, Jalife J, Berenfeld O, and Kalifa J (2008) Atrial septopulmonary bundle of the posterior left atrium provides a substrate for atrial fibrillation initiation in a model of vagally mediated pulmonary vein tachycardia of the structurally normal heart. Circ Arrhythm Electrophysiol 1:175-183.

Køber L, Torp-Pedersen C, McMurray JJ, Gøtzsche O, Lévy S, Crijns H, Amlie J, and Carlsen J; Dronedarone Study Group (2008) Increased mortality after dronedarone therapy for severe heart failure. $N$ Engl J Med 358:2678-2687.

Kockskämper J, Zima AV, Roderick HL, Pieske B, Blatter LA, and Bootman MD (2008) Emerging roles of inositol 1,4,5-trisphosphate signaling in cardiac myocytes. J Mol Cell Cardiol 45:128-147.

Kovoor P, Wickman K, Maguire CT, Pu W, Gehrmann J, Berul CI, and Clapham DE (2001) Evaluation of the role of $\mathrm{I}(\mathrm{KACh})$ in atrial fibrillation using a mouse knockout model. J Am Coll Cardiol 37:2136-2143.

Kuhn EW, Liakopoulos OJ, Stange S, Deppe AC, Slottosch I, Choi YH, and Wahlers T (2014) Preoperative statin therapy in cardiac surgery: a meta-analysis of 90,000 patients. Eur J Cardiothorac Surg 45:17-26, discussion 26.

Lafuente-Lafuente C, Valembois L, Bergmann JF, and Belmin J (2015) Antiarrhythmics for maintaining sinus rhythm after cardioversion of atrial fibrillation. Cochrane Database Syst Rev 2015:CD005049.

Lalevée N, Nargeot J, Barrére-Lemaire S, Gautier P, and Richard S (2003) Effects of amiodarone and dronedarone on voltage-dependent sodium current in human cardiomyocytes. J Cardiovasc Electrophysiol 14:885-890.

Lavall D, Selzer C, Schuster P, Lenski M, Adam O, Schäfers HJ, Böhm M, and Laufs $\mathrm{U}$ (2014) The mineralocorticoid receptor promotes fibrotic remodeling in atrial fibrillation. J Biol Chem 289:6656-6668.

Le Heuzey JY, De Ferrari GM, Radzik D, Santini M, Zhu J, and Davy JM (2010) A short-term, randomized, double-blind, parallel-group study to evaluate the efficacy and safety of dronedarone versus amiodarone in patients with persistent atrial fibrillation: the DIONYSOS study. J Cardiovasc Electrophysiol 21:597-605.

Li Q, Huang H, Liu G, Lam K, Rutberg J, Green MS, Birnie DH, Lemery R, Chahine $\mathrm{M}$, and Gollob MH (2009) Gain-of-function mutation of Nav1.5 in atrial fibrillation enhances cellular excitability and lowers the threshold for action potential firing. Biochem Biophys Res Commun 380:132-137.

Liang X, Xie H, Zhu PH, Hu J, Zhao Q, Wang CS, and Yang C (2009) Enhanced activity of inositol-1,4,5-trisphosphate receptors in atrial myocytes of atrial fibrillation patients. Cardiology 114:180-191.

Linz DK, Afkham F, Itter G, Rütten H, and Wirth KJ (2007) Effect of atrial electrica remodeling on the efficacy of antiarrhythmic drugs: comparison of amiodarone with $\mathrm{I}(\mathrm{Kr})$ - and I(to)/IKur-blockade in vivo. J Cardiovasc Electrophysiol 18:1313-1320. Lip GY, Tse HF, and Lane DA (2012) Atrial fibrillation. Lancet 379:648-661.

Lubitz SA, Yi BA, and Ellinor PT (2010a) Genetics of atrial fibrillation. Heart Fail Clin 6:239-247.

Lubitz SA, Yin X, Fontes JD, Magnani JW, Rienstra M, Pai M, Villalon ML, Vasan RS, Pencina MJ, Levy D, et al. (2010b) Association between familial atrial fibrillation and risk of new-onset atrial fibrillation. JAMA 304:2263-2269.

Machida T, Hashimoto N, Kuwahara I, Ogino Y, Matsuura J, Yamamoto W, Itano Y, Zamma A, Matsumoto R, Kamon J, et al. (2011) Effects of a highly selective acetylcholine-activated $\mathrm{K}+$ channel blocker on experimental atrial fibrillation. Circ Arrhythm Electrophysiol 4:94-102.

Mackenzie L, Bootman MD, Laine M, Berridge MJ, Thuring J, Holmes A, Li WH and Lipp P (2002) The role of inositol 1,4,5-trisphosphate receptors in $\mathrm{Ca}(2+)$ signalling and the generation of arrhythmias in rat atrial myocytes. $J$ Physiol $\mathbf{5 4 1}$ 395-409.

Mackinnon AC, Gibbons MA, Farnworth SL, Leffler H, Nilsson UJ, Delaine T, Simpson AJ, Forbes SJ, Hirani N, Gauldie J, et al. (2012) Regulation of transforming growth factor TGF- $\beta 1$-driven lung fibrosis by galectin-3. Am $J$ Respir Crit Care Med 185:537-546.

Makary S, Voigt N, Maguy A, Wakili R, Nishida K, Harada M, Dobrev D, and Nattel $\mathrm{S}$ (2011) Differential protein kinase $\mathrm{C}$ isoform regulation and increased constitutive activity of acetylcholine-regulated potassium channels in atrial remodeling. Circ Res 109:1031-1043.

Mancarella S, Yue Y, Karnabi E, Qu Y, El-Sherif N, and Boutjdir M (2008) Impaired $\mathrm{Ca} 2+$ homeostasis is associated with atrial fibrillation in the alpha1D L-type Ca2+ channel KO mouse. Am J Physiol Heart Circ Physiol 295:H2017-H2024.

Mann SA, Otway R, Guo G, Soka M, Karlsdotter L, Trivedi G, Ohanian M, Zodgekar P, Smith RA, Wouters MA, et al. (2012) Epistatic effects of potassium channel variation on cardiac repolarization and atrial fibrillation risk. J Am Coll Cardiol 59:1017-1025. Martins RP, Kaur K, Hwang E, Ramirez RJ, Willis BC, Filgueiras-Rama D, Ennis SR, Takemoto Y, Ponce-Balbuena D, Zarzoso M, et al. (2014) Dominant frequency increase rate predicts transition from paroxysmal to long-term persistent atrial fibrillation. Circulation 129:1472-1482.

Matsuo S, Lim KT, and Haissaguerre M (2007) Ablation of chronic atrial fibrillation. Heart Rhythm 4:1461-1463. 
Matsushima S, Tsutsui H, and Sadoshima J (2014) Physiological and pathological functions of NADPH oxidases during myocardial ischemia-reperfusion. Trends Cardiovasc Med 24:202-205.

Mazurek T, Zhang L, Zalewski A, Mannion JD, Diehl JT, Arafat H, Sarov-Blat L, O'Brien S, Keiper EA, Johnson AG, et al. (2003) Human epicardial adipose tissue is a source of inflammatory mediators. Circulation 108:2460-2466.

Meng Z, Tan J, He Q, Zhu M, Li X, Zhang J, Jia Q, Wang S, Zhang G, and Zheng W (2015) Wenxin keli versus sotalol for paroxysmal atrial fibrillation caused by hyperthyroidism: a prospective, open label, and randomized study. Evid Based Complement Alternat Med 2015:101904.

Miyasaka Y, Barnes ME, Gersh BJ, Cha SS, Bailey KR, Abhayaratna WP, Seward JB, and Tsang TS (2006) Secular trends in incidence of atrial fibrillation in Olmsted County, Minnesota, 1980 to 2000, and implications on the projections for future prevalence. Circulation 114:119-125.

Moe GK and Abildskov JA (1959) Atrial fibrillation as a self-sustaining arrhythmia independent of focal discharge. Am Heart $J$ 58:59-70.

Morel E, Meyronet D, Thivolet-Bejuy F, and Chevalier P (2008) Identification and distribution of interstitial Cajal cells in human pulmonary veins. Heart Rhythm $\mathbf{5}$ 1063-1067.

Muñoz V, Grzeda KR, Desplantez T, Pandit SV, Mironov S, Taffet SM, Rohr S, Kléber AG, and Jalife J (2007) Adenoviral expression of IKs contributes to wavebreak and fibrillatory conduction in neonatal rat ventricular cardiomyocyte monolayers. Circ Res 101:475-483.

Murphy NF, Simpson CR, Jhund PS, Stewart S, Kirkpatrick M, Chalmers J, MacIntyre K, and McMurray JJ (2007) A national survey of the prevalence, incidence, primary care burden and treatment of atrial fibrillation in Scotland. Heart 93: $606-612$

Narayan SM and Jalife J (2014) CrossTalk proposal: rotors have been demonstrated to drive human atrial fibrillation. J Physiol 592:3163-3166.

Narayan SM, Krummen DE, Enyeart MW, and Rappel W (2012) Computational mapping approach identifies stable and long-lived electrical rotors and focal sources in human atrial fibrillation. PLoS One 7:e46034.

Nattel S (2015) Changes in the atrial transcriptome and atrial fibrillation: susceptibility, persistence, causes, and consequences. Circ Arrhythm Electrophysiol 8:5-7.

Nattel S, Burstein B, and Dobrev D (2008) Atrial remodeling and atrial fibrillation: mechanisms and implications. Circ Arrhythm Electrophysiol 1:62-73.

Nattel S and Harada M (2014) Atrial remodeling and atrial fibrillation: recent advances and translational perspectives. J Am Coll Cardiol 63:2335-2345.

Nattel S, Maguy A, Le Bouter S, and Yeh YH (2007) Arrhythmogenic ion-channel remodeling in the heart: heart failure, myocardial infarction, and atrial fibrillation. Physiol Rev 87:425-456.

Neefs J, van den Berg NW, Limpens J, Berger WR, Boekholdt SM, Sanders P, and de Groot JR (2017) Aldosterone pathway blockade to prevent atrial fibrillation: a systematic review and meta-analysis. Int $J$ Cardiol 231:155-161.

Nielsen JB, Fritsche LG, Zhou W, Teslovich TM, Holmen OL, Gustafsson S, Gabrielsen ME, Schmidt EM, Beaumont R, Wolford BN, et al. (2018) Genome-wide study of atrial fibrillation identifies seven risk loci and highlights biological pathways and regulatory elements involved in cardiac development. Am J Hum Genet 102 : 103-115.

Ninio DM and Saint DA (2008) The role of stretch-activated channels in atrial fibrillation and the impact of intracellular acidosis. Prog Biophys Mol Biol 97: 401-416.

Nishida K, Michael G, Dobrev D, and Nattel S (2010) Animal models for atrial fibrillation: clinical insights and scientific opportunities. Europace 12:160-172.

Noma A (1983) ATP-regulated K+ channels in cardiac muscle. Nature 305:147-148.

Noujaim SF, Pandit SV, Berenfeld O, Vikstrom K, Cerrone M, Mironov S, Zugermayr M, Lopatin AN, and Jalife J (2007) Up-regulation of the inward rectifier K+ current (I K1) in the mouse heart accelerates and stabilizes rotors. $J$ Physiol 578:315-326.

Noujaim SF, Stuckey JA, Ponce-Balbuena D, Ferrer-Villada T, López-Izquierdo A Pandit S, Calvo CJ, Grzeda KR, Berenfeld O, Chapula JA, et al. (2010) Specific residues of the cytoplasmic domains of cardiac inward rectifier potassium channels are effective antifibrillatory targets. FASEB $J$ 24:4302-4312.

Noujaim SF, Stuckey JA, Ponce-Balbuena D, Ferrer-Villada T, López-Izquierdo A, Pandit SV, Sánchez-Chapula JA, and Jalife J (2011) Structural bases for the differen anti-fibrillatory effects of chloroquine and quinidine. Cardiovasc Res 89:862-869.

Novo G, Guttilla D, Fazio G, Cooper D, and Novo S (2008) The role of the reninangiotensin system in atrial fibrillation and the therapeutic effects of ACE-Is and ARBS. Br J Clin Pharmacol 66:345-351.

O'Connell RP, Musa H, Gomez MS, Avula UM, Herron TJ, Kalifa J, and Anumonwo JM (2015) Free fatty acid effects on the atrial myocardium: membrane ionic currents are remodeled by the disruption of T-tubular architecture. PLoS One 10 e0133052.

Olson TM, Alekseev AE, Liu XK, Park S, Zingman LV, Bienengraeber M, Sattiraju S, Ballew JD, Jahangir A, and Terzic A (2006) Kv1.5 channelopathy due to KCNA5 loss-of-function mutation causes human atrial fibrillation. Hum $\mathrm{Mol}$ Genet 15: 2185-2191.

Opel A, Nobles M, Montaigne D, Finlay M, Anderson N, Breckenridge R, and Tinker A (2015) Absence of the regulator of G-protein signaling, RGS4, predisposes to atrial fibrillation and is associated with abnormal calcium handling. J Biol Chem 290:19233-19244.

Ouvrard-Pascaud A, Sainte-Marie Y, Bénitah JP, Perrier R, Soukaseum C, Nguyen Dinh Cat A, Royer A, Le Quang K, Charpentier F, Demolombe S, et al. (2005) Conditional mineralocorticoid receptor expression in the heart leads to lifethreatening arrhythmias. Circulation 111:3025-3033.

Oyen N, Ranthe MF, Carstensen L, Boyd HA, Olesen MS, Olesen SP, Wohlfahrt J, and Melbye M (2012) Familial aggregation of lone atrial fibrillation in young persons. J Am Coll Cardiol 60:917-921.

Padfield GJ, Steinberg C, Swampillai J, Qian H, Connolly SJ, Dorian P, Green MS, Humphries KH, Klein GJ, Sheldon R, et al. (2017) Progression of paroxysmal to persistent atrial fibrillation: 10-year follow-up in the Canadian registry of atrial fibrillation. Heart Rhythm 14:801-807.
Pammolli F, Magazzini L, and Riccaboni M (2011) The productivity crisis in pharmaceutical R\&D. Nat Rev Drug Discov 10:428-438.

Pandit SV and Jalife J (2013) Rotors and the dynamics of cardiac fibrillation. Circ Res 112:849-862.

Pappone C, Radinovic A, Manguso F, Vicedomini G, Ciconte G, Sacchi S, Mazzone P Paglino G, Gulletta S, Sala S, et al. (2008) Atrial fibrillation progression and management: a 5-year prospective follow-up study. Heart Rhythm 5:1501-1507.

Pappone C, Santinelli V, Manguso F, Vicedomini G, Gugliotta F, Augello G, Mazzone P, Tortoriello V, Landoni G, Zangrillo A, et al. (2004) Pulmonary vein denervation enhances long-term benefit after circumferential ablation for paroxysmal atrial fibrillation. Circulation 109:327-334.

Parvez B, Vaglio J, Rowan S, Muhammad R, Kucera G, Stubblefield T, Carter S, Roden D, and Darbar D (2012) Symptomatic response to antiarrhythmic drug therapy is modulated by a common single nucleotide polymorphism in atrial fibrillation. J Am Coll Cardiol 60:539-545.

Pathak RK, Elliott A, Middeldorp ME, Meredith M, Mehta AB, Mahajan R, Hendriks JM, Twomey D, Kalman JM, Abhayaratna WP, et al. (2015) Impact of CARDIOrespiratory FITness on arrhythmia recurrence in obese individuals with atrial fibrillation: the CARDIO-FIT study. J Am Coll Cardiol 66:985-996.

Patterson E, Lazzara R, Szabo B, Liu H, Tang D, Li YH, Scherlag BJ, and Po SS (2006) Sodium-calcium exchange initiated by the $\mathrm{Ca} 2+$ transient: an arrhythmia trigger within pulmonary veins. J Am Coll Cardiol 47:1196-1206.

Pavri BB, Greenberg HE, Kraft WK, Lazarus N, Lynch JJ, Salata JJ, Bilodeau MT, Regan CP, Stump G, Fan L, et al. (2012) MK-0448, a specific Kv1.5 inhibitor: safety, pharmacokinetics, and pharmacodynamic electrophysiology in experimental animal models and humans. Circ Arrhythm Electrophysiol 5:1193-1201.

Pegan S, Arrabit C, Zhou W, Kwiatkowski W, Collins A, Slesinger PA, and Choe S (2005) Cytoplasmic domain structures of Kir2.1 and Kir3.1 show sites for modulating gating and rectification. Nat Neurosci 8:279-287.

Perez-Lugones A, McMahon JT, Ratliff NB, Saliba WI, Schweikert RA, Marrouche NF, Saad EB, Navia JL, McCarthy PM, Tchou P, et al. (2003) Evidence of specialized conduction cells in human pulmonary veins of patients with atrial fibrillation. J Cardiovasc Electrophysiol 14:803-809.

Piccini JP, Hammill BG, Sinner MF, Jensen PN, Hernandez AF, Heckbert SR, Benjamin EJ, and Curtis LH (2012) Incidence and prevalence of atrial fibrillation and associated mortality among Medicare beneficiaries, 1993-2007. Circ Cardiovasc Qual Outcomes 5:85-93.

Podd SJ, Freemantle N, Furniss SS, and Sulke N (2016) First clinical trial of specific IKACh blocker shows no reduction in atrial fibrillation burden in patients with paroxysmal atrial fibrillation: pacemaker assessment of BMS 914392 in patients with paroxysmal atrial fibrillation. Europace 18:340-346.

Pogwizd SM, Schlotthauer K, Li L, Yuan W, and Bers DM (2001) Arrhythmogenesis and contractile dysfunction in heart failure: roles of sodium-calcium exchange, inward rectifier potassium current, and residual beta-adrenergic responsiveness. Circ Res 88:1159-1167.

Potpara TS, Stankovic GR, Beleslin BD, Polovina MM, Marinkovic JM, Ostojic MC and Lip GYH (2012) A 12-year follow-up study of patients with newly diagnosed lone atrial fibrillation: implications of arrhythmia progression on prognosis: the Belgrade atrial fibrillation study. Chest 141:339-347.

Pouliopoulos J, Chik WW, Kanthan A, Sivagangabalan G, Barry MA, Fahmy PN Midekin C, Lu J, Kizana E, Thomas SP, et al. (2013) Intramyocardial adiposity after myocardial infarction: new implications of a substrate for ventricular tachycardia. Circulation 128:2296-2308.

Ramu Y, Klem AM, and Lu Z (2004) Short variable sequence acquired in evolution enables selective inhibition of various inward-rectifier K+ channels. Biochemistry 43:10701-10709.

Ravelli F and Allessie M (1997) Effects of atrial dilatation on refractory period and vulnerability to atrial fibrillation in the isolated Langendorff-perfused rabbit heart. Circulation 96:1686-1695.

Ravens U, Poulet C, Wettwer E, and Knaut M (2013) Atrial selectivity of antiarrhythmic drugs. $J$ Physiol 591:4087-4097.

Ravens U and Wettwer E (2011) Ultra-rapid delayed rectifier channels: molecular basis and therapeutic implications. Cardiovasc Res 89:776-785.

Rennison JH and Van Wagoner DR (2009) Impact of dietary fatty acids on cardiac arrhythmogenesis. Circ Arrhythm Electrophysiol 2:460-469.

Riemer TL, Sobie EA, and Tung L (1998) Stretch-induced changes in arrhythmogenesis and excitability in experimentally based heart cell models. Am J Physio 275:H431-H442.

Rienstra M, Hobbelt AH, Alings M, Tijssen JGP, Smit MD, Brugemann J, Geelhoed B, Tieleman RG, Hillege HL, Tukkie R, et al. (2018) Targeted therapy of underlying conditions improves sinus rhythm maintenance in patients with persistent atrial fibrillation: results of the RACE 3 trial. Eur Heart $J$ :ehx739.

Rossman EI, Liu K, Morgan GA, Swillo RE, Krueger JA, Gardell SJ, Butera J, Gruver M, Kantrowitz J, Feldman HS, et al. (2009) The gap junction modifier, GAP-134 [(2S,4R)-1-(2-aminoacetyl)-4-benzamido-pyrrolidine-2-carboxylic acid] improves conduction and reduces atrial fibrillation/flutter in the canine sterile pericarditis model. J Pharmacol Exp Ther 329:1127-1133.

Salvador-Montañés O, Gómez-Gallanti A, Garofalo D, Noujaim SF, Peinado R, and Filgueiras-Rama D (2012) Polyunsaturated fatty acids in atrial fibrillation: looking for the proper candidates. Front Physiol 3:370.

Samie FH, Berenfeld O, Anumonwo J, Mironov SF, Udassi S, Beaumont J, Taffet S, Pertsov AM, and Jalife J (2001) Rectification of the background potassium current: a determinant of rotor dynamics in ventricular fibrillation. Circ Res 89:1216-1223.

Sanders P, Berenfeld O, Hocini M, Jaïs P, Vaidyanathan R, Hsu LF, Garrigue S, Takahashi Y, Rotter M, Sacher F, et al. (2005) Spectral analysis identifies sites of high-frequency activity maintaining atrial fibrillation in humans. Circulation 112 : 789-797.

Sardar MR, Saeed W, and Kowey PR (2016) Antiarrhythmic drug therapy for atrial fibrillation. Heart Fail Clin 12:205-221.

Sarmast F, Kolli A, Zaitsev A, Parisian K, Dhamoon AS, Guha PK, Warren M, Anumonwo JM, Taffet SM, Berenfeld O, et al. (2003) Cholinergic atrial fibrillation: 
$\mathrm{I}(\mathrm{K}, \mathrm{ACh})$ gradients determine unequal left/right atrial frequencies and rotor dynamics. Cardiovasc Res 59:863-873.

Scornik FS, Desai M, Brugada R, Guerchicoff A, Pollevick GD, Antzelevitch C, and Pérez GJ (2006) Functional expression of "cardiac-type" Nav1.5 sodium channel in canine intracardiac ganglia. Heart Rhythm 3:842-850.

Schauerte P, Scherlag BJ, Patterson E, Scherlag MA, Matsudaria K, Nakagawa H, Lazzara R, and Jackman WM (2001) Focal atrial fibrillation: experimental evidence for a pathophysiologic role of the autonomic nervous system. $J$ Cardiovasc Electrophysiol 12:592-599.

Schmidt C, Wiedmann F, Kallenberger SM, Ratte A, Schulte JS, Scholz B, Müller FU, Voigt N, Zafeiriou MP, Ehrlich JR, et al. (2017a) Stretch-activated two-poredomain $\left(\mathrm{K}_{2 \mathrm{P}}\right)$ potassium channels in the heart: focus on atrial fibrillation and heart failure. Prog Biophys Mol Biol 130 (Pt B):233-243.

Schmidt C, Wiedmann F, Schweizer PA, Becker R, Katus HA, and Thomas D (2012) Novel electrophysiological properties of dronedarone: inhibition of human cardiac two-pore-domain potassium (K2P) channels. Naunyn Schmiedebergs Arch Pharmacol 385:1003-1016.

Schmidt C, Wiedmann F, Voigt N, Zhou XB, Heijman J, Lang S, Albert V, Kallenberger S, Ruhparwar A, Szabó G, et al. (2015) Upregulation of K(2P)3.1 K+ current causes action potential shortening in patients with chronic atrial fibrillation. $\mathrm{Cir}$ culation 132:82-92.

Schmidt C, Wiedmann F, Zhou XB, Heijman J, Voigt N, Ratte A, Lang S, Kallenberger SM, Campana C, Weymann A, et al. (2017b) Inverse remodelling of K2P3.1 $\mathrm{K}+$ channel expression and action potential duration in left ventricular dysfunction and atrial fibrillation: implications for patient-specific antiarrhythmic drug therapy. Eur Heart $J$ 38:1764-1774.

Schnabel RB, Sullivan LM, Levy D, Pencina MJ, Massaro JM, D’Agostino RB Sr, Newton-Cheh C, Yamamoto JF, Magnani JW, Tadros TM, et al. (2009) Development of a risk score for atrial fibrillation (Framingham Heart Study): a communitybased cohort study. Lancet 373:739-745.

Schram G, Pourrier M, Melnyk P, and Nattel S (2002) Differential distribution of cardiac ion channel expression as a basis for regional specialization in electrical function. Circ Res 90:939-950.

Sheehan KA and Blatter LA (2003) Regulation of junctional and non-junctional sarcoplasmic reticulum calcium release in excitation-contraction coupling in cat atrial myocytes. J Physiol 546:119-135.

Shiroshita-Takeshita A, Sakabe M, Haugan K, Hennan JK, and Nattel S (2007) Model-dependent effects of the gap junction conduction-enhancing antiarrhythmic peptide rotigaptide (ZP123) on experimental atrial fibrillation in dogs. Circulation 115:310-318.

Singh BN (2008) Amiodarone as paradigm for developing new drugs for atrial fibrillation. J Cardiovasc Pharmacol 52:300-305.

Skibsbye L, Poulet C, Diness JG, Bentzen BH, Yuan L, Kappert U, Matschke K, Wettwer E, Ravens U, Grunnet M, et al. (2014) Small-conductance calciumactivated potassium (SK) channels contribute to action potential repolarization in human atria. Cardiovasc Res 103:156-167.

Stump GL, Wallace AA, Regan CP, and Lynch JJ Jr (2005) In vivo antiarrhythmic and cardiac electrophysiologic effects of a novel diphenylphosphine oxide IKur blocker (2-isopropyl-5-methylcyclohexyl) diphenylphosphine oxide. J Pharmacol Exp Ther 315:1362-1367.

Swartz MF, Fink GW, Lutz CJ, Taffet SM, Berenfeld O, Vikstrom KL, Kasprowicz K, Bhatta L, Puskas F, Kalifa J, et al. (2009) Left versus right atrial difference in dominant frequency, $\mathrm{K}(+)$ channel transcripts, and fibrosis in patients developing atrial fibrillation after cardiac surgery. Heart Rhythm 6:1415-1422.

Takemoto Y, Ramirez RJ, Kaur K, Salvador-Montañés O, Ponce-Balbuena D, RamosMondragón R, Ennis SR, Guerrero-Serna G, Berenfeld O, and Jalife J (2017) Eplerenone reduces atrial fibrillation burden without preventing atrial electrical remodeling. J Am Coll Cardiol 70:2893-2905.

Takemoto Y, Ramirez RJ, Yokokawa M, Kaur K, Ponce-Balbuena D, Sinno MC, Willis BC, Ghanbari H, Ennis SR, Guerrero-Serna G, et al. (2016) Galectin-3 regulates atrial fibrillation remodeling and predicts catheter ablation outcomes. JACC Basic Transl Sci 1:143-154.

Takemoto Y, Slough DP, Meinke G, Katnik C, Graziano ZA, Chidipi B, Reiser M, Alhadidy MM, Ramirez R, Salvador-Montanes O, et al. (2018) Structural basis for the antiarrhythmic blockade of a potassium channel with a small molecule. FASEB $J$ 32:1778-1793.

Talajic M, DeRoode MR, and Nattel S (1987) Comparative electrophysiologic effects of intravenous amiodarone and desethylamiodarone in dogs: evidence for clinically relevant activity of the metabolite. Circulation 75:265-271.

Tanaka K, Zlochiver S, Vikstrom KL, Yamazaki M, Moreno J, Klos M, Zaitsev AV, Vaidyanathan R, Auerbach DS, Landas S, et al. (2007) Spatial distribution of fibrosis governs fibrillation wave dynamics in the posterior left atrium during heart failure. Circ Res 101:839-847.

Tanner RM, Baber U, Carson AP, Voeks J, Brown TM, Soliman EZ, Howard VJ, and Muntner P (2011) Association of the metabolic syndrome with atrial fibrillation among United States adults (from the REasons for Geographic and Racial Differences in Stroke [REGARDS] study). Am J Cardiol 108:227-232.

Thanassoulis G, Massaro JM, O'Donnell CJ, Hoffmann U, Levy D, Ellinor PT, Wang TJ, Schnabel RB, Vasan RS, Fox CS, et al. (2010) Pericardial fat is associated with prevalent atrial fibrillation: the Framingham Heart Study. Circ Arrhythm Electrophysiol 3:345-350.

Tinker A, Finlay M, Nobles M, and Opel A (2016) The contribution of pathways initiated via the Gq1 G-protein family to atrial fibrillation. Pharmacol Res 105:54-61.
Torp-Pedersen C, Raev DH, Dickinson G, Butterfield NN, Mangal B, and Beatch GN (2011) A randomized, placebo-controlled study of vernakalant (oral) for the prevention of atrial fibrillation recurrence after cardioversion. Circ Arrhythm Electrophysiol 4:637-643.

Tsai WC, Chan YH, Hsueh CH, Everett TH IV, Chang PC, Choi EK, Olaopa MA, Lin SF, Shen C, Kudela MA, et al. (2016) Small conductance calcium-activated potassium current and the mechanism of atrial arrhythmia in mice with dysfunctional melanocyte-like cells. Heart Rhythm 13:1527-1535.

Van Wagoner DR (2003) Electrophysiological remodeling in human atrial fibrillation. Pacing Clin Electrophysiol 26:1572-1575.

Van Wagoner DR, Pond AL, Lamorgese M, Rossie SS, McCarthy PM, and Nerbonne JM (1999) Atrial L-type Ca2+ currents and human atrial fibrillation. Circ Res 85 428-436.

Vaquero M, Calvo D, and Jalife J (2008) Cardiac fibrillation: from ion channels to rotors in the human heart. Heart Rhythm 5:872-879.

Venteclef N, Guglielmi V, Balse E, Gaborit B, Cotillard A, Atassi F, Amour J, Leprince P, Dutour A, Clement K, and Hatem SN (2015) Human epicardial adipose tissue induces fibrosis of the atrial myocardium through the secretion of adipofibrokines. Eur Heart $J$ 36:795-805a.

Voigt N, Trausch A, Knaut M, Matschke K, Varró A, Van Wagoner DR, Nattel S, Ravens U, and Dobrev D (2010) Left-to-right atrial inward rectifier potassium current gradients in patients with paroxysmal versus chronic atrial fibrillation. Circ Arrhythm Electrophysiol 3:472-480.

Walsh KB (2015) Targeting cardiac potassium channels for state-of-the-art drug discovery. Expert Opin Drug Discov 10:157-169.

Wang TM, Chiang CE, Sheu JR, Tsou CH, Chang HM, and Luk HN (2003) Homogenous distribution of fast response action potentials in canine pulmonary vein sleeves: a contradictory report. Int J Cardiol 89:187-195.

Wang Z, Fermini B, and Nattel S (1993) Sustained depolarization-induced outward current in human atrial myocytes. Evidence for a novel delayed rectifier K+ current similar to Kv1.5 cloned channel currents. Circ Res 73:1061-1076.

Warren M, Guha PK, Berenfeld O, Zaitsev A, Anumonwo JM, Dhamoon AS, Bagwe S, Taffet SM, and Jalife J (2003) Blockade of the inward rectifying potassium current terminates ventricular fibrillation in the guinea pig heart. $J$ Cardiovasc Electrophysiol 14:621-631.

Weng LC, Choi SH, Klarin D, Smith JG, Loh PR, Chaffin M, Roselli C, Hulme OL, Lunetta KL, Dupuis J, et al. (2017a) Heritability of atrial fibrillation. Circ Cardiovasc Genet 10: e001838.

Weng LC, Preis SR, Hulme OL, Larson MG, Choi SH, Wang B, Trinquart L, McManus DD, Staerk L, Lin H, et al. (2018) Genetic predisposition, clinical risk factor burden, and lifetime risk of atrial fibrillation. Circulation 137:1027-1038.

Wickramasinghe SR and Patel VV (2013) Local innervation and atrial fibrillation. Circulation 128:1566-1575.

Wijffels MC, Kirchhof CJ, Dorland R, and Allessie MA (1995) Atrial fibrillation begets atrial fibrillation. A study in awake chronically instrumented goats. Circulation 92:1954-1968.

Wit AL and Boyden PA (2007) Triggered activity and atrial fibrillation. Heart Rhythm 4(3 Suppl):S17-S23.

Wong CX, Abed HS, Molaee P, Nelson AJ, Brooks AG, Sharma G, Leong DP, Lau DH, Middeldorp ME, Roberts-Thomson KC, et al. (2011) Pericardial fat is associated with atrial fibrillation severity and ablation outcome. J Am Coll Cardiol 57: $1745-1751$.

Wyse DG, Van Gelder IC, Ellinor PT, Go AS, Kalman JM, Narayan SM, Nattel S, Schotten U, and Rienstra M (2014) Lone atrial fibrillation: does it exist? J Am Coll Cardiol 63:1715-1723.

Xia M, Jin Q, Bendahhou S, He Y, Larroque MM, Chen Y, Zhou Q, Yang Y, Liu Y, Liu B, et al. (2005) A Kir2.1 gain-of-function mutation underlies familial atrial fibrillation. Biochem Biophys Res Commun 332:1012-1019.

Xu Y, Tuteja D, Zhang Z, Xu D, Zhang Y, Rodriguez J, Nie L, Tuxson HR, Young JN, Glatter KA, et al. (2003) Molecular identification and functional roles of a $\mathrm{Ca}(2+)$-activated $\mathrm{K}+$ channel in human and mouse hearts. $J$ Biol Chem 278:49085-49094.

Xue X, Guo D, Sun H, Wang D, Li J, Liu T, Yang L, Shu J, and Yan GX (2013) Wenxin Keli suppresses ventricular triggered arrhythmias via selective inhibition of late sodium current. Pacing Clin Electrophysiol 36:732-740.

Yamazaki M, Vaquero LM, Hou L, Campbell K, Zlochiver S, Klos M, Mironov S, Berenfeld O, Honjo H, Kodama I, et al. (2009) Mechanisms of stretch-induced atrial fibrillation in the presence and the absence of adrenocholinergic stimulation: interplay between rotors and focal discharges. Heart Rhythm 6:1009-1017.

Yu T, Deng C, Wu R, Guo H, Zheng S, Yu X, Shan Z, Kuang S, and Lin Q (2012 Decreased expression of small-conductance $\mathrm{Ca} 2+$-activated $\mathrm{K}+$ channels SK1 and SK2 in human chronic atrial fibrillation. Life Sci 90:219-227.

Zannad F, McMurray JJ, Krum H, van Veldhuisen DJ, Swedberg K, Shi H, Vincent J, Pocock SJ, and Pitt B; EMPHASIS-HF Study Group (2011) Eplerenone in patients with systolic heart failure and mild symptoms. N Engl J Med 364:11-21.

Zhang X, Zhang S, Li Y, Detrano RC, Chen K, Li X, Zhao L, Benjamin EJ, and Wu Y (2009) Association of obesity and atrial fibrillation among middle-aged and elderly Chinese. Int J Obes 33:1318-1325.

Zoni-Berisso M, Lercari F, Carazza T, and Domenicucci S (2014) Epidemiology of atrial fibrillation: European perspective. Clin Epidemiol 6:213-220.

Zygmunt AC, Nesterenko VV, Rajamani S, Hu D, Barajas-Martinez H, Belardinelli L, and Antzelevitch C (2011) Mechanisms of atrial-selective block of $\mathrm{Na}^{+}$channels by ranolazine: I. Experimental analysis of the use-dependent block. Am J Physiol Heart Circ Physiol 301:H1606-H1614. 